\title{
The lamprey respiratory network: Some evolutionary aspects
}

\author{
Donatella Mutolo, Fulvia Bongianni, Tito Pantaleo, Elenia Cinelli * \\ Dipartimento di Medicina Sperimentale e Clinica, Sezione Scienze Fisiologiche, Università degli Studi di Firenze, Viale G.B. Morgagni 63, 50134, Firenze, Italy
}

\section{A R T I C L E I N F O}

Edited by M. Dutschmann

\section{Keywords:}

Evolution of breathing

Paratrigeminal respiratory group

5-HT

ATP

GABA and glycine

Astrocytes

\begin{abstract}
A B S T R A C T
Breathing is a complex behaviour that involves rhythm generating networks. In this review, we examine the main characteristics of respiratory rhythm generation in vertebrates and, in particular, we describe the main results of our studies on the role of neural mechanisms involved in the neuromodulation of the lamprey respiration. The lamprey respiratory rhythm generator is located in the paratrigeminal respiratory group (pTRG) and shows similarities with the mammalian preBötzinger complex. In fact, within the pTRG a major role is played by glutamate, but also GABA and glycine display important contributions. In addition, neuromodulatory influences are exerted by opioids, substance P, acetylcholine and serotonin. Both structures respond to exogenous ATP with a biphasic response and astrocytes there located strongly contribute to the modulation of the respiratory pattern. The results emphasize that some important characteristics of the respiratory rhythm generating network are, to a great extent, maintained throughout evolution.
\end{abstract}

\section{Introduction}

Breathing is a complex behaviour that requires sophisticated control mechanisms enabling animals to respond properly to physiological challenges and changing environmental conditions. Like locomotion and other rhythmic behaviours for which the motor pattern is generated within the brainstem and/or spinal cord without the need for peripheral or suprapontine inputs, breathing originates from a central rhythmogenic circuit. It is well known that there are similarities in the topography and functional characteristics between groups of respirationrelated neurons in the hindbrain of different vertebrate groups (see $e$. g. Taylor et al., 1999, 2010). Therefore, a comparative approach among vertebrates may provide important insights into how multiple rhythmic circuits become functionally intertwined to produce and coordinate respiratory behaviours. There are also important differences related to the specific modes of vertebrates' respiration. Fish typically propel water in a unidirectional fashion over the gills using ventilatory muscles operating around the jaws, the branchial muscles and the opercular muscles in teleosts. In the amphibian tadpole larvae ventilation is maintained by the activity of cranial muscles, while in the adult amphibians a buccal force pump contributes to both gill and lung breathing. Reptiles are the first group of vertebrates to use a thoracic aspiration pump to ventilate the lungs. Although they typically lack a diaphragm per $s e$, the presence of the diaphragmaticus muscle contributes to creating the negative pressure necessary for lung ventilation. In mammals, lung ventilation is realized through coordinate contractions of diaphragmatic, intercostal and/or abdominal muscles along with some accessory respiratory muscles. The respiratory system in birds resembles that of mammals, but they lack a diaphragm and their lungs are ventilated by volume changes in the air sacs.

In the present review, we examine the main characteristics of the control of breathing in vertebrates and, in particular, we describe the main results of our studies concerning neural mechanisms involved in respiratory rhythm generation and its modulation within the lamprey respiratory network. The lamprey central nervous system may represent an ideal model to provide insights into the basic neural mechanisms of rhythmic activities, such as locomotion and respiration, owing to the presence of fewer neurons than in higher vertebrates and the experimental advantage that it can be maintained in vitro along with spontaneous respiratory activity (Grillner, 2003, 2006).

\section{A few notes on evolutionary aspects of vertebrate respiration}

The mammalian breathing rhythm arises from the preBötzinger complex (preBötC), a medullary neural network essential for normal breathing and widely recognized as necessary and sufficient to generate the inspiratory phase of respiration (Smith et al., 1991; for reviews see Feldman et al., 2013; Del Negro et al., 2018). This region has been identified in several mammal species, including goats, cats, rabbits, rats, mice and humans (Smith et al., 1991; Schwarzacher et al., 1995, 2011;

\footnotetext{
* Corresponding author.

E-mail address: elenia.cinelli@unifi.it (E. Cinelli).
} 
Ramirez et al., 1996, 1998; Wenninger et al., 2004; Mutolo et al., 2005; Bongianni et al., 2010; Pantaleo et al., 2011; Tupal et al., 2014; Iovino et al., 2019; Cinelli et al., 2020a; see e.g. Del Negro et al., 2018). In mammals, the breathing cycle is generally divided into three phases, i.e. inspiration, postinspiration or expiratory phase 1 , and expiratory phase 2 (active expiration) based on the activity of the diaphragm and vocal fold adduction muscles. It has been proposed that three anatomically distinct coupled excitatory microcircuits generate the three phases of the respiratory cycle ("triple-oscillator" hypothesis; Ramirez et al., 2016; Anderson and Ramirez, 2017; Del Negro et al., 2018). The preBötC generates inspiration, while a medullary region named postinspiratory complex (PiCo) probably generates postinspiration (Anderson et al., 2016), and the retrotrapezoid nucleus/parafacial respiratory group (RTN/pFRG), especially as far as a lateral portion of the pFRG is concerned, generates active expiration (Janczewski and Feldman, 2006; Abdala et al., 2009; Abbott et al., 2011). Inhibition typically coordinates the timing of each phase, and rhythmicity within each microcircuit is controlled by a balance between recurrent synaptic excitation, inhibition and intrinsic bursting properties (Ramirez and Baertsch, 2018; Ashhad and Feldman, 2020). However, some recent findings in the rat do not seem to agree with this view, suggesting that respiratory pattern formation engages distributed neuronal populations within the different brainstem respiratory compartments (Von Euler, 1997; Mutolo et al., 2002; Smith et al., 2007; Jones and Dutschmann, 2016; Dhingra et al., 2019, 2020; Toor et al., 2019).

Rhythm-generating networks are likely present in early vertebrates, but studies in non-mammalian vertebrates are rather limited. A single microcircuit located in a region rostrolateral to the trigeminal motor nucleus is present in the lamprey (Rovainen, 1983, 1985; Russell, 1986; Thompson, 1985; Bongianni et al., 1999, 2002, 2006; Martel et al., 2007a; Mutolo et al., 2007, 2010, 2011; Cinelli et al., 2013, 2014, 2016, 2017, 2020b; for review see Bongianni et al., 2016; Milsom, 2018), a jawless fish that diverged from the main vertebrate line about 560 million years ago (Kumar and Hedges, 1998). This neural aggregate, termed the paratrigeminal respiratory group (pTRG), is necessary and sufficient for rhythm generation driving gill movements that can be recorded primarily from the vagus nerve (for review see Bongianni et al., 2016).

The localization of the lamprey respiratory rhythm generator close to the trigeminal nucleus is not surprising since the evolutionary origin of respiratory mechanisms in vertebrates is from structures and pumps initially associated with feeding and trigeminal control (Rovainen, 1996; Kinkead, 2009; Milsom, 2010; Taylor et al., 2010). At this stage, the trigeminal motor mechanism is the first mover in the respiratory sequence that also involves other cranial motor nuclei. It is implicated in velar pumping in larval lampreys (Homma, 1975) and in buccal pumping in jawed fishes (Taylor et al., 2010). Metamorphosis from larval to adult lampreys involves extensive remodeling of the head with regression and replacement of most muscles and the transition from a sedentary filter feeding to parasitic blood feeding (Rovainen, 1996). In adult lampreys, the velum becomes a valve that separates the buccal cavity from the pharyngeal cavity and allows the production of a tidal breathing when the mouth is engaged in feeding (Kinkead, 2009).

The neuronal organization of the lamprey respiratory network differs from that suggested for gill rhythm generator in jawed fish, where the respiratory rhythm-generating network seems to span the length of the brainstem (Duchcherer et al., 2010; Taylor et al., 2010). Fish exhibit continuous rhythmical breathing movements of the buccal and septal or opercular pumps. The nerves innervating their respiratory muscles include mainly the trigeminal along with the facial, glossopharyngeal and vagus nerves (Taylor et al., 2010). A longitudinal strip of neurons with spontaneous respiration-related bursting activity has been identified throughout the whole extent of the medulla, indicating a distributed organization of respiration rhythm generating neurons in the reticular formation (Taylor et al., 1999, 2010 also for further Refs.). Simultaneous recordings of efferent activity from the central cut ends of the nerves innervating the respiratory muscles revealed that the trigeminal nerve fires before the facial, glossopharyngeal and vagus nerves, thus suggesting that the trigeminal motor mechanism plays a predominant role in the respiratory sequence (Taylor, 1992; Taylor et al., 2009). However, it should be mentioned that in jawed fish the presence of a main respiratory rhythm generator homologous to the lamprey pTRG as well as of neural structures similar to the mammal pFRG has not been reported.

On the contrary, localized respiratory microcircuits have been described in the isolated brainstem of post-metamorphic bullfrogs. The isolated brainstem preparation produces a biphasic respiratory rhythm similar to that described in adult frogs, i.e. the buccal and the lung ventilation (Wilson et al., 2002; Baghdadwala et al., 2015, 2016), even if buccal bursts are not always observed in preparations from adult animals (Janes et al., 2019). Two brainstem sites have been identified: the caudal buccal area responsible for the generation of buccal bursts and the rostral lung area responsible for the generation of the lung bursts, also referred to as lung powerstroke generator. Importantly, when the two sites are separated by transection both rostral and caudal brainstem sections could generate independent bursts, thus suggesting that the amphibian respiratory network is composed of at least two distinct, but interacting oscillators (Wilson et al., 2002). More recently, it has been suggested the presence of a third brainstem oscillator named priming burst generator, possibly involved in the generation of the initial portion of lung bursts (Baghdadwala et al., 2015, 2016). This view of multiple oscillators reminds the "triple-oscillator" hypothesis proposed for mammals (Ramirez et al., 2016; Anderson and Ramirez, 2017; Del Negro et al., 2018).

Turtles generate positive and negative air pressures in their lungs (Johnson and Mitchell, 1998) by alternately moving their pectoral and pelvic girdles inward (expiration) and outward (inspiration). The respiratory cycle consists of three distinct phases, i.e. inspiration, a long breath-hold and expiration. This organization recalls the three-phase model for respiratory rhythm proposed for mammals (Richter, 1982). In particular, the breath-hold could remind the postinspiratory phase. The isolated adult turtle brainstem is capable of producing fictive breathing with a pattern of discharge similar to that observed in vivo (Douse and Mitchell, 1990) and is relatively insensitive to hypoxia (Johnson et al., 1998). Several types of bulbar respiratory neurons with patterns of discharge similar to those described in mammals have been found in different sites of the medulla (Takeda et al., 1986). A more recent study in vitro confirmed the presence of different classes of respiratory neurons, including intrinsically-bursting neurons (pacemaker neurons), throughout an extended region of the turtle medulla. Intrinsic bursting properties were especially abundant in postinspiratory neurons, but the significance of this finding is not clear (Johnson et al., 2016). Studies on the neural mechanisms underlying rhythm generation indicate that under conditions of synaptic inhibition blockade in vitro, the turtle respiratory network can produce a rhythm sensitive to opiates and increased $\mathrm{CO}_{2}$ via an expiratory, rather than an inspiratory pacemaker-driven mechanism (Johnson et al., 2002). The role of pacemaker neurons in producing respiratory rhythm remains uncertain. Noticeably, the blockade of $\mathrm{Ca}^{++}$-activated cation current $\left(\mathrm{I}_{\mathrm{CAN}}\right)$ with flufenamic acid during synaptic blockade abolished respiratory motor output (Johnson et al., 2007). These data indicate that the turtle expiratory oscillator has as a possible underlying rhythm generating mechanism the "group-pacemaker" model proposed in mammals (Del Negro et al., 2005, 2018; Feldman and Del Negro, 2006). The location and mechanisms underlying respiratory rhythm generation in the reptile brainstem require further investigations to be defined.

Birds, like mammals, typically breathe continuously and rhythmically. However, they do not have a diaphragm, and lung volume appears to vary little over the respiratory cycle. The mechanical production of tidal flows employs air sacs that require active muscle contractions for both inspiration and expiration (Bouverot, 1978). There are limited examples of respiration-related neural recordings from nuclei in the avian hindbrain, but data suggest the presence of a rostrocaudal column 
extending from the pons to the spinomedullary junction, with respiration-related regions possibly corresponding to those observed in mammals (Whitaker-Fornek et al., 2019). A recent study in birds reports the presence of two independent embryonic respiratory rhythms recorded from the IX cranial nerve. One rhythm, characterized by short duration episodes, appears only transient during development, while the other (long duration episodes) persists throughout life (Vincen-Brown et al., 2016). The emergence of long duration episodes is reminiscent of breathing patterns in frogs and other intermittent breathers in which long-related motor outflows occur in clusters separated by silent periods of variable lengths (Douse and Mitchell, 1992; Kinkead and Milsom, 1997; Straus et al., 2000; for review see Milsom, 1991). The physiological relevance of these two rhythms is yet to be determined, but they may represent an example of coupled oscillators in early development. To our knowledge, no association has been described between the emergence of these long duration episodes and changes in metabolic states, such as those observed during sleep or hibernation in some endothermic vertebrates (see e.g. Milsom and Jackson, 2011).

\section{Characterization of the lamprey PTRG}

Breathing in the adult lamprey is produced by synchronous contractions of the branchial muscles that pump water in and out of gill pores. Exhalation is the only active process produced by muscle contractions which compress the branchial basket, while inhalation is passive and occurs when the branchial basket expands by passive recoil during muscle relaxation, drawing fresh water back into the sacs (Rovainen, 1977, 1979). The respiratory motoneurons are located in three distinct motor nuclei, i.e. the facial, glossopharyngeal and, especially, vagal nuclei, each corresponding to a cranial nerve. The facial nerve innervates the anterior muscles of the first gill, the glossopharyngeal nerve innervates the posterior muscles of the first gill and the anterior muscles of the second gill, while the vagus nerve innervates the rest of the gills (see Guimond et al., 2003; Missaghi et al., 2016; Figs. 1A and $2 \mathrm{~A}$, left panel). The isolated brainstem of the adult lamprey spontaneously generates respiratory neuronal activity in vitro (fictive respiration). Under these experimental conditions, the respiratory frequency is similar to that of spontaneous respiration of intact lampreys in the aquarium at $9-10{ }^{\circ} \mathrm{C}$ (Rovainen, 1977, 1983; Thompson, 1985; Russell, 1986; Bongianni et al., 1999, 2002, 2006; Martel et al., 2007a; Mutolo et al., 2007, 2010, 2011; Cinelli et al., 2013, 2014, 2016, 2017, 2020b). Most of the research on respiratory rhythm generation in lampreys comes from in vitro experiments where the input from pTRG to respiratory motoneurons is phasic. Studies in in vivo preparations are lacking. However, it seems reasonable to consider that the phasic input from the pTRG to motoneuronal areas would be the same even if modulated by sensory afferents that obviously are removed under in vitro conditions.

Baseline (fast) respiratory activity is interrupted by prolonged bursts of vagal activity followed by a short pause and slight changes in respiratory frequency (Fig. 1B). These bursts, also called 'coughs', occur at lower and irregular frequency (Rovainen, 1977; Thompson, 1985; Martel et al., 2007a) and probably do not originate from the pTRG (see also Hoffman et al., 2016; Cinelli et al., 2017, 2020b). These prolonged bursts (slow rhythm) were described for the first time in vitro by Rovainen (1974). They could also be induced by mechanical stimulation of the gill openings or electrical stimulation of the vagus nerve (Rovainen, 1974, 1977). Their function, similar to that of cough in mammals, could be related to the removal of particles obstructing the gills (Rovainen, 1977, 1979, 1985; Thompson, 1985). Similarly, coughing is a reflex initiated by sensory inputs and under chemoreceptor modulation (see e.g. Mutolo, 2017). However, the prolonged bursts in lampreys are also rhythmically produced in the isolated brainstem. The slow rhythm seems to be generated in the caudal half of the rhombencephalon since it persists in the respiratory motoneurons after a transection below the trigeminal motor nuclei while the fast rhythm ceases in motoneurons, but is still present in the pTRG neurons (Martel et al., 2007a). Interestingly, Hoffman et al. (2016) found in the larval lamprey that the periodic prolonged busts are modulated by central sensitivity to $\mathrm{CO}_{2}$ both in vivo and in vitro. The presence of central $\mathrm{CO}_{2} / \mathrm{pH}$-sensitive chemoreceptors may have provided an important substrate for the evolution of vertebrate air-breathing (Hoffman et al., 2016). Recently, we showed in the adult lampreys that reducing the $\mathrm{pH}$ of the perfusing solution from 7.4 to 7.0 at constant $P_{\mathrm{CO} 2}$ causes increases in respiratory frequency and peak vagal activity of the fast rhythm, suggesting that a $\mathrm{CO}_{2}$-independent $\mathrm{pH}$ sensory mechanism is present in the neuronal respiratory network of the lamprey (Cinelli et al., 2017).

As already mentioned above, the neural aggregate responsible for respiratory rhythmogenesis in the lamprey has been named pTRG. The position of the pTRG is illustrated in Fig. 2A. The pTRG is located in a region rostrolateral to the trigeminal motor nucleus within a restricted area of the rostral rhombencephalon at the level of the isthmic Müller cell $\mathrm{I}_{1}$ close to the sulcus limitans of His. Anatomical boundaries of the pTRG are also confirmed by injections of neuronal tracers into the vagal motoneuronal pool to retrogradely label neurons projecting to respiratory motoneurons (Cinelli et al., 2013). Respiration-related neurons

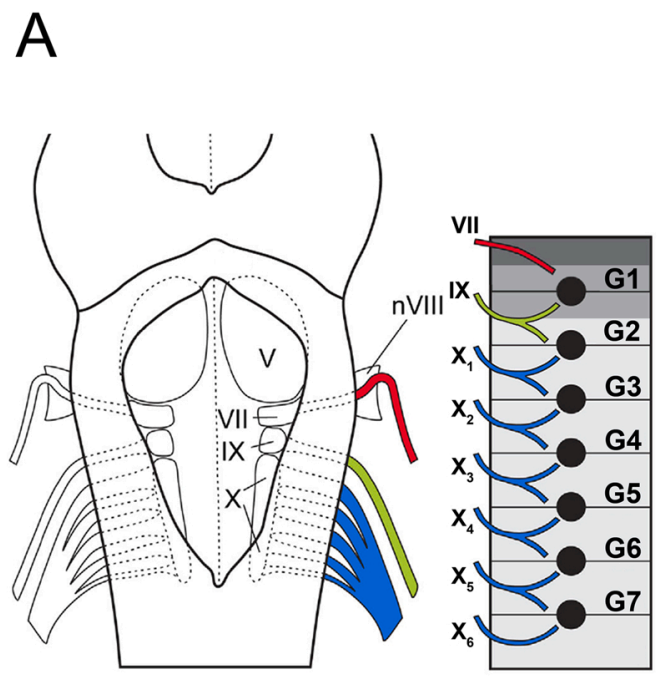

B
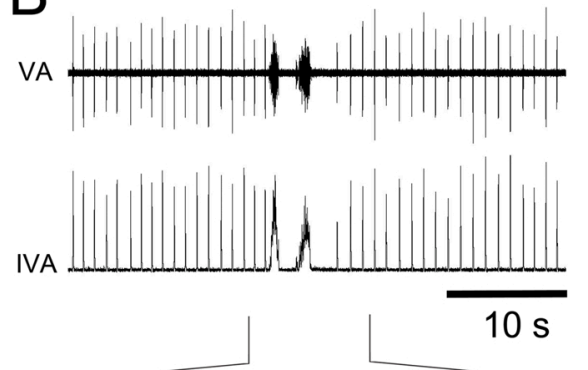

VA

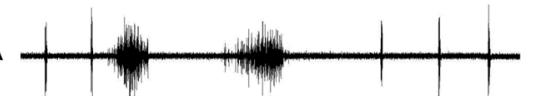

IVA

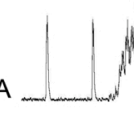

Fig. 1. Central distribution of respiratory motoneurons, gill innervation and respiratory activity in adult lampreys. A: schematic illustration of a dorsal view of the lamprey brainstem showing the localization of facial (VII), glossopharyngeal (IX) and vagal (X) motor nuclei (left) and the pattern of innervation of the seven pairs of gills (G1-G7) by VII, IX and $\mathrm{X}$ cranial nerves (right). Filled circles, gill pores; V, trigeminal motor nucleus; nVIII, vestibular nerve; $\mathrm{X}_{1}-\mathrm{X}_{6}$, branchial branches of the vagus nerve. Illustration are not to scale (adapted from Guimond et al., 2003 and Missaghi et al., 2016). B: example of typical recordings from the vagal nerve in in vitro isolated brainstems showing the ongoing (fast) respiratory activity and the presence of 'coughs', reported also with an expanded time scale. VA, raw vagal nerve activity; IVA, integrated vagal nerve activity. 
A
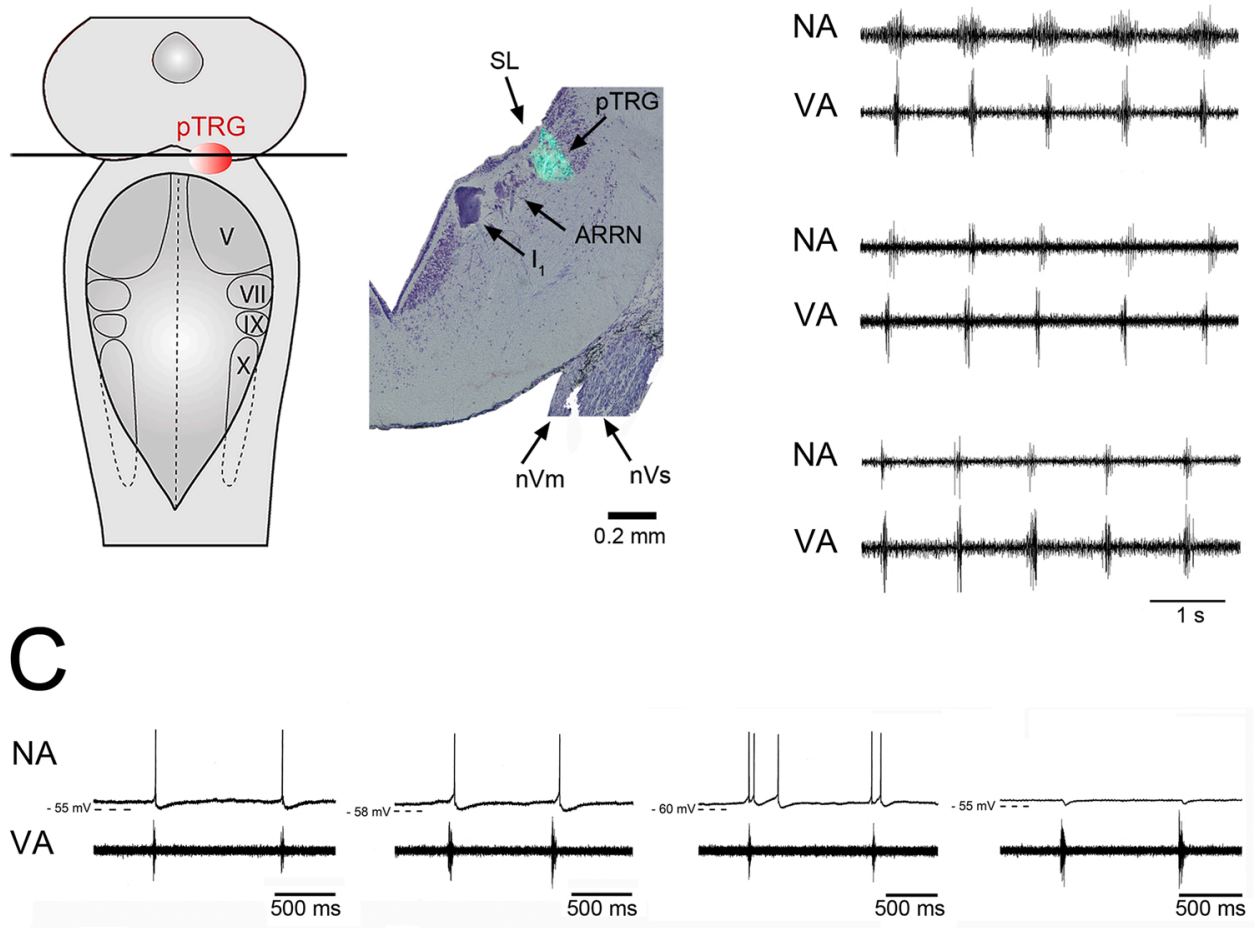

D

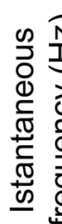

DAMGO microinjections

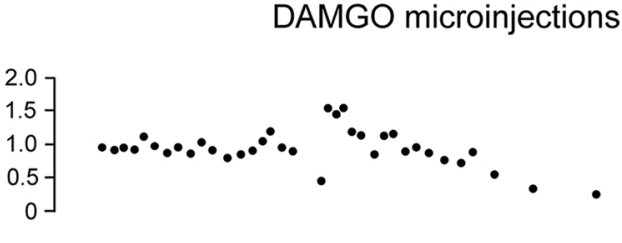

VA

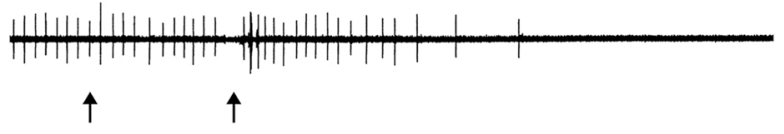

Fig. 2. Criteria for the localization and characterization of the paratrigeminal respiratory group (pTRG). A (left): schematic illustration of a dorsal view of the lamprey mesencephalon/ rhombencephalon showing the location of the pTRG (red area). V, trigeminal motor nucleus; VII, facial motor nucleus; IX, glossopharyngeal motor nucleus; X, vagal motor nucleus. A (right): photomicrograph of a coronal section at the level of the pTRG (unbroken line in the left panel) showing an example of the location of fluorescent beads (green) added to neuroactive agent solutions microinjected into the pTRG. The histological section is counterstained with Cresyl violet. Light-field and fluorescence photomicrographs have been superimposed. ARRN, anterior rhombencephalic reticular nucleus; $\mathrm{I}_{1}$, isthmic Müller cell; $\mathrm{nVm}$, motor root of the trigeminal nerve; nVs, sensory root of the trigeminal nerve; SL, sulcus limitans of His. The ARRN and $\mathrm{I}_{1}$ were used as anatomical landmarks to identify the pTRG region. B: extracellular recordings of respiration-related neuronal activities encountered in the pTRG region showing different discharge patterns. Traces are extracellular neuronal activity (NA) and raw vagal motoneuronal activity (VA). Discharge patterns of neurons starting firing before the onset of vagal bursts, at the end of vagal bursts, and synchronously with vagal bursts are shown (from top to bottom). C: intracellular recordings of respiration-related neuronal activities encountered in the PTRG region showing a neuron firing synchronously with vagal bursts, a neuron firing at the end of vagal bursts, a neuron firing before and after the onset of vagal bursts, and a neuron that displayed hyperpolarization during the vagal bursts (from left to right). Traces are intracellular neuronal activity (NA) and raw vagal motoneuronal activity (VA). D: cessation of vagal bursts caused by bilateral microinjections of $1 \mathrm{mM}$ DAMGO into the pTRG region. Microinjections indicated by arrows. VA, raw vagal nerve activity. Modified from Mutolo et al. (2007, 2010) and Cinelli et al. (2020b). with different discharge patterns are encountered in the pTRG (Fig. 2B, C; see also Mutolo et al., 2007, 2010). The presence of neurons starting firing just before or at the end of vagal bursts, as well as synchronously with vagal bursts supports the hypothesis that the PTRG likely has a crucial role in respiratory rhythmogenesis. Noticeably, respiration-related neurons with different discharge patterns have been described within the preBötC of different mammal species (see e.g. Connelly et al., 1992; Rekling and Feldman, 1998; Schwarzacher et al., 1995; St Jacques and St John, 1999; Sun et al., 1998; Smith et al., 2000; Mutolo et al., 2002; Hayes and Del Negro, 2007; Bongianni et al., 2008, 2010; Ramirez et al., 2016 also for further Refs.). Further evidence on the key role of the pTRG in the lamprey respiratory rhythmogenesis is supported by the finding that local application of the $\mu$-opioid receptor agonist [D-Ala2, N-Me-Phe4, Gly5-ol]-enkephalin (DAMGO) induced the cessation of respiratory activity (Mutolo et al., 2007; see Fig. 2D). Like in mammals where the preBötC plays an important role in the genesis of the respiratory depression induced by $\mu$-opioid receptors in in vivo and in vitro preparations (Gray et al., 1999; Montandon et al., 2011, 2016; Qi et al., 2017; Sun et al., 2019; Cinelli et al., 2020a), also in the lamprey the pTRG is sensitive to opioids, indicating that the inhibitory influence of these peptides on the respiratory rhythm is highly conserved in vertebrates.

The hypothesis that the PTRG region is crucial for respiratory rhythm generation is corroborated by respiratory responses obtained after its blockade or activation. Unilateral microinjections of a mixture of the NMDA (D-AP5) or non-NMDA (CNQX) receptor antagonists or the $\mathrm{GABA}_{\mathrm{A}}$ receptor agonist muscimol suppress respiratory activity (Cinelli et al., 2013). Examples of these responses are reported in Fig. 3A and B. Furthermore, also the view that changes in respiratory frequency are due to an action on the central mechanisms generating the respiratory rhythm (Gray et al., 1999; Bongianni et al., 2008; Feldman and Del Negro, 2006; Del Negro et al., 2018; Ramirez and Baertsch, 2018) fits the hypothesis that the pTRG corresponds to the respiratory rhythm generator (Mutolo et al., 2007, 2010, 2011; Cinelli et al., 2013, 2014). Indeed, the activation of the PTRG area through microinjections of a mixture of glutamate agonists (AMPA and NMDA) increases the respiratory frequency and peak vagal activity (Fig. 3C).

It is interesting to recall that Rovainen (1985) suggested that a crossed pathway, emerging from the generators on both sides of the brain participated in the bilateral synchronization of respiration. 
A
Control

Right VA

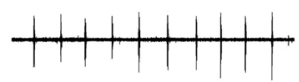

Left VA

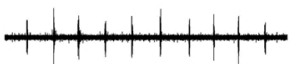

Recovery $5 \mathrm{mM}$ D-AP5

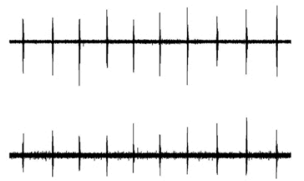

Fig. 3. Respiratory responses after blockade or activation of the pTRG. A: suppression of respiratory rhythmic activity about 1 min after unilateral microinjections into the pTRG region of a mixture of $1 \mathrm{mM}$ CNQX and $5 \mathrm{mM}$ D-AP5. B: similar effects on respiration induced about $1 \mathrm{~min}$ after the completion of unilateral microinjections into the pTRG region of $0.2 \mathrm{mM}$ muscimol. C: increases in respiratory frequency and peak vagal activity about $2 \mathrm{~min}$ after unilateral microinjection of a mixture of $1 \mathrm{mM}$ AMPA and $2 \mathrm{mM}$ NMDA into the pTRG. VA, raw vagal nerve activity. Modified from Cinelli et al. (2013).

B

\section{Control $\quad 0.2 \mathrm{mM}$ muscimol Recovery}
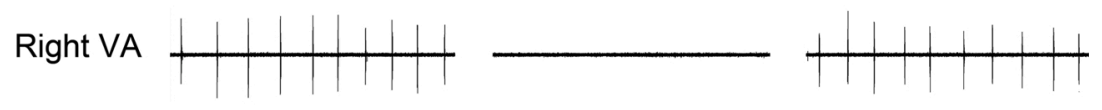

C

Control

$1 \mathrm{mM}$ AMPA +

Recovery 2 mM NMDA

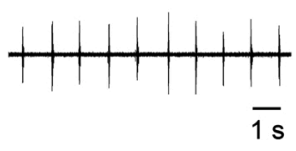

Right VA
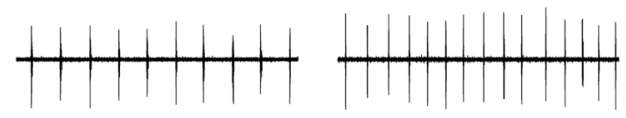

$1 \mathrm{~s}$

Furthermore, a transverse hemi-section caudal to the trigeminal motor nucleus abolishes the fast rhythm recorded extracellularly in ipsilateral, but not contralateral vagal motoneurons (Thompson, 1985). Several lines of evidence indicate that neurons located in the PTRG project to the ipsilateral and contralateral vagal motor nucleus as well as to the contralateral pTRG (Rovainen, 1985; Thompson, 1985; Russell, 1986; Gariepy et al., 2012; Cinelli et al., 2013). Thus, the bilateral effects obtained with unilateral microinjections may be explained by the presence of bilateral projections of pTRG neurons to respiratory motoneurons and reciprocal connections between the two pTRGs (Cinelli et al., 2013, 2014).

\section{Comparison between the pTRG and the preBötC}

\subsection{General features}

The crucial role of the PTRG in lamprey respiratory rhythm generation recalls that attributed to the mammalian preBötC (see e.g. Smith et al., 1991; Bongianni et al., 2016; Cinelli et al., 2017; Del Negro et al., 2018; Ramirez and Baertsch, 2018). The two rhythm generators exhibit many similarities. Excitatory and inhibitory amino acids have a prominent role in both neural networks that are under extensive neuromodulatory control and display sensitivity to opioids, substance P (SP), acetylcholine (ACh), serotonin (5-HT) and ATP (Mutolo et al., 2007, 2010, 2011; Cinelli et al., 2013, 2017; Iovino et al., 2019; see also Doi and Ramirez, 2008). In this context, it seems appropriate to recall that even though the PTRG and the preBötC have similar functional characteristics within the breathing network, they do not appear to be homologous from an embryonic point of view. The PTRG is located in the rostral rhombencephalon/isthmic region corresponding to the rostral pons in mammals and arises from rhombomeres 2-3 (Murakami et al., 2004; Funk, 2017; Milsom, 2018), while the preBötC is located in the medulla and derives from rhombomeres 7-8 (Champagnat and Fortin, 1997; Gray, 2013; Ramirez et al., 2016). In mammals, respiratory neurons are present in the rostral pons at the level of the parabrachial complex and Kölliker-Fuse nuclei. These nuclei play a modulatory role in adjusting the breathing pattern to various stimuli and in respiratory phase transition (see e.g. Dutschmann and Dick, 2012). Whether the pontine nuclei have some features homologous to that of the lamprey pTRG remains to be investigated.

Widely accepted findings indicate that glutamatergic transmission is critical for respiratory rhythmogenesis within the preBötC (Greer et al., 1991; Mutolo et al., 2005; Wallen-Mackenzie et al., 2006; for review see Del Negro et al., 2018; Ramirez et al., 2016; Ramirez and Baertsch, 2018). As already mentioned, also in the lamprey pTRG the endogenous tonic release of excitatory amino acids plays a crucial role in respiratory rhythmogenesis acting on ionotropic receptors (Bongianni et al., 1999; Martel et al., 2007a; Mutolo et al., 2011; Cinelli et al., 2013, 2014) and exerts a modulatory role on respiration via metabotropic receptors (Bongianni et al., 2002). The majority of preBötC glutamatergic neurons express neurokinin-1 $\left(\mathrm{NK}_{1}\right)$ receptors for which $\mathrm{SP}$ is the ligand that exerts excitatory effects on respiratory activity in in vitro and in vivo preparations (Gray et al., 1999, 2001; Wang et al., 2002; Peña and Ramirez, 2004; McKay et al., 2005; Fong and Potts, 2006; Hayes and Del Negro, 2007). Interestingly, we have shown by using retrograde tracers and immunohistochemistry that the pTRG contains glutamatergic neurons, surrounded by an intense SP immunoreactivity, with axonal projections to the vagal motor nucleus (Cinelli et al., 2013). Accordingly, microinjections of $\mathrm{SP}$ as well as $\mathrm{NK}_{1}, \mathrm{NK}_{2}$ and $\mathrm{NK}_{3}$ receptor agonists into the PTRG increase the frequency and amplitude of vagal bursts (Mutolo et al., 2010).

Synaptic inhibition has an important modulatory role within the mammalian preBötC. However, the blockade of both $\mathrm{GABA}_{\mathrm{A}}$ and glycine receptors does not stop breathing. A pattern of breathing characterized by the presence of double bursts has recently been reported by increasing neuronal excitability of the preBötC through blockade of inhibitory synaptic transmission both in in vitro and in vivo preparations (e.g. Bongianni et al., 2010; Kam et al., 2013; Janczewski et al., 2013; Sherman et al., 2015; Cui et al., 2016; for review see Feldman and Smith, 1989; Ramirez et al., 2016; Del Negro et al., 2018; Ramirez and Baertsch, 2018). This also occurs, at least in part, in the pTRG where GABAergic mechanisms acting through $G_{A B A}$ and $G A B A_{B}$ receptors 
have a tonic modulatory role on respiration, while a glycinergic tonic influence is lacking (Cinelli et al., 2014, 2020b). Microinjections of gabazine, a selective $\mathrm{GABA}_{\mathrm{A}}$ receptor antagonist, into the pTRG induce a pattern of breathing characterized by rhythmic activity assembled in multiple bursts that progressively developed and stabilized in a double-bursts pattern (Fig. 4A). Endogenous activation of $\mathrm{GABA}_{\mathrm{A}}$ receptors may conceivably represent a mechanism to control mainly the excitability of pTRG neurons and to generate a more regular respiratory rhythm. Microinjections of CGP 35348, a selective $\mathrm{GABA}_{B}$ receptor antagonist, into the PTRG induce only modest decreases in respiratory frequency probably due to a presynaptic mechanism (Fig. 4B), while microinjections of strychnine, a glycine receptor antagonist, do not provoke any obvious or consistent effect on respiratory activity (Fig. 4C). Interestingly, GABAergic inhibition modulates the pTRG not only under basal conditions but also during apnea induced by blockade of glutamatergic transmission. Under this condition, the removal of GABAergic transmission causes the resumption of rhythmic respiratory activity. The presence of intense GABA immunoreactivity surrounding pTRG neurons retrogradely labelled by neurobiotin injected into the vagal motoneurons region corroborates these findings (Cinelli et al., 2014).

Both GABA and glycine-mediated inhibition may represent modulatory mechanisms for the activity of excitatory glutamatergic neurons projecting to the lamprey rhythm generating respiratory network. In more detail, GABAergic and glycinergic inputs to glutamatergic neurons within the vagal, the facial and the glossopharyngeal regions mediate changes in respiratory frequency through ascending excitatory projections. Consistently, neurons projecting to the pTRG are immunoreactive for glutamate, surrounded by GABA immunoreactive structures and associated with the presence of glycinergic cells (Cinelli et al., 2016). Several regions of the lamprey brain contain GABAergic neurons
(Robertson et al., 2007; Villar-Cervino et al., 2008) and may represent possible sources of inhibition to PTRG neurons or glutamatergic neurons projecting to the PTRG from the vagal area. In particular, a population of GABA-immunoreactive cells located in the isthmic region (see Robertson et al., 2007), i.e. a site very close to the central respiratory rhythm generator, could play a role in the control of pTRG neuron excitability either directly or indirectly through an action on projecting neurons located in the vagal area.

Another intriguing issue that strengthens similarities between the pTRG and the preBötC is the functional role in the lamprey respiratory network of the burst promoting currents, i.e. the persistent $\mathrm{Na}^{+}$current $\left(\mathrm{I}_{\mathrm{NaP}}\right)$ and the $\mathrm{I}_{\mathrm{CAN}}$. Bath application of either riluzole to block $\mathrm{I}_{\mathrm{NaP}}$ or flufenamic acid to block $I_{\text {CAN }}$ does not suppress respiratory activity, while co-application of both blockers abolishes the respiratory rhythm that, however, is restarted by SP microinjected into the pTRG (Mutolo et al., 2010). An example of these effects has been reported in Fig. 5. These findings are similar to those reported for mammalian preBötC and explained by SP-induced excitation that initiates a positive feedback throughout recurrent excitation leading to resumption of rhythmic respiratory activity according to the "group-pacemaker" hypothesis (Del Negro et al., 2005; Feldman and Del Negro, 2006; Del Negro et al., 2018).

\subsection{Cholinergic modulation}

In mammals, ACh plays an important role in the neural control of breathing. Increases in respiratory frequency are produced by the activation of both nicotinic ACh receptors (nAChRs) and muscarinic ACh receptors (mAChRs) within the preBötC in in vitro preparations from neonatal rodents (Shao and Feldman, 2000, 2001, 2009). Interestingly, also in the lamprey ACh exerts an excitatory influence on respiratory

\section{A}

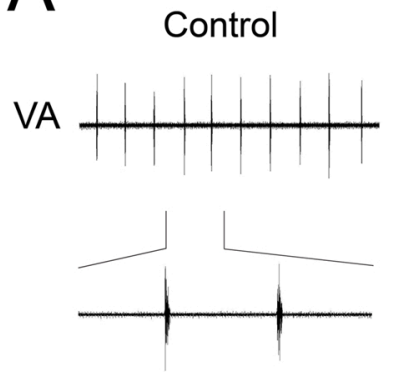

B
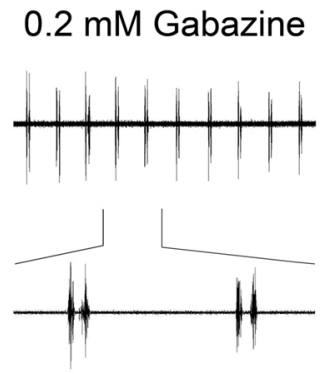

25 mM CGP 35348

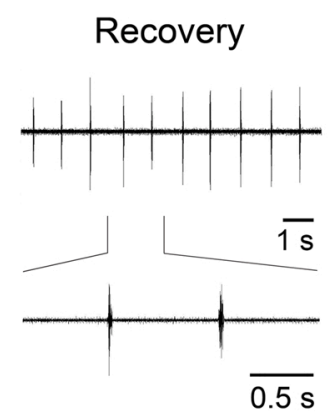

Recovery
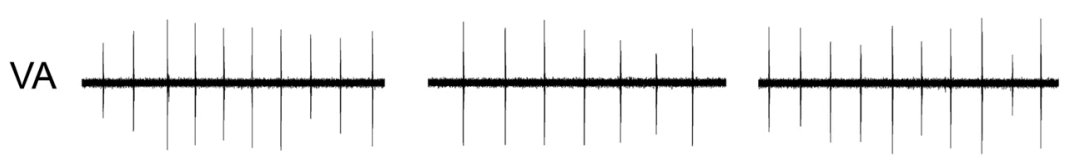

$\overline{1 s}$

\section{Control \\ $1 \mathrm{mM}$ Strychnine}

VA

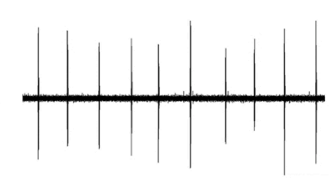

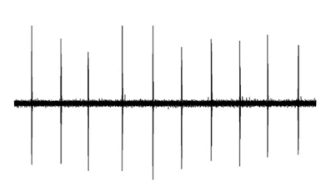

Fig. 4. Respiratory role of $\mathrm{GABA}_{\mathrm{A}}, \mathrm{GABA}_{\mathrm{B}}$ and glycine receptors within the pTRG. A: bilateral microinjections of $0.2 \mathrm{mM}$ gabazine into the pTRG cause the appearance of vagal bursts grouped in duplets within $5 \mathrm{~min}$ after the completion of the injections. An example of vagal bursts during control period, gabazine-induced effects and recovery is shown with an expanded timescale below each trace. B: decrease in respiratory frequency about $15 \mathrm{~min}$ after bilateral microinjections of 25 mM CGP 35,348 into the pTRG. C: the absence of appreciable respiratory effects about $3 \mathrm{~min}$ after bilateral microinjections of $1 \mathrm{mM}$ strychnine into the pTRG. VA, raw vagal nerve activity. Modified from Cinelli et al. (2014). 


\section{Control}

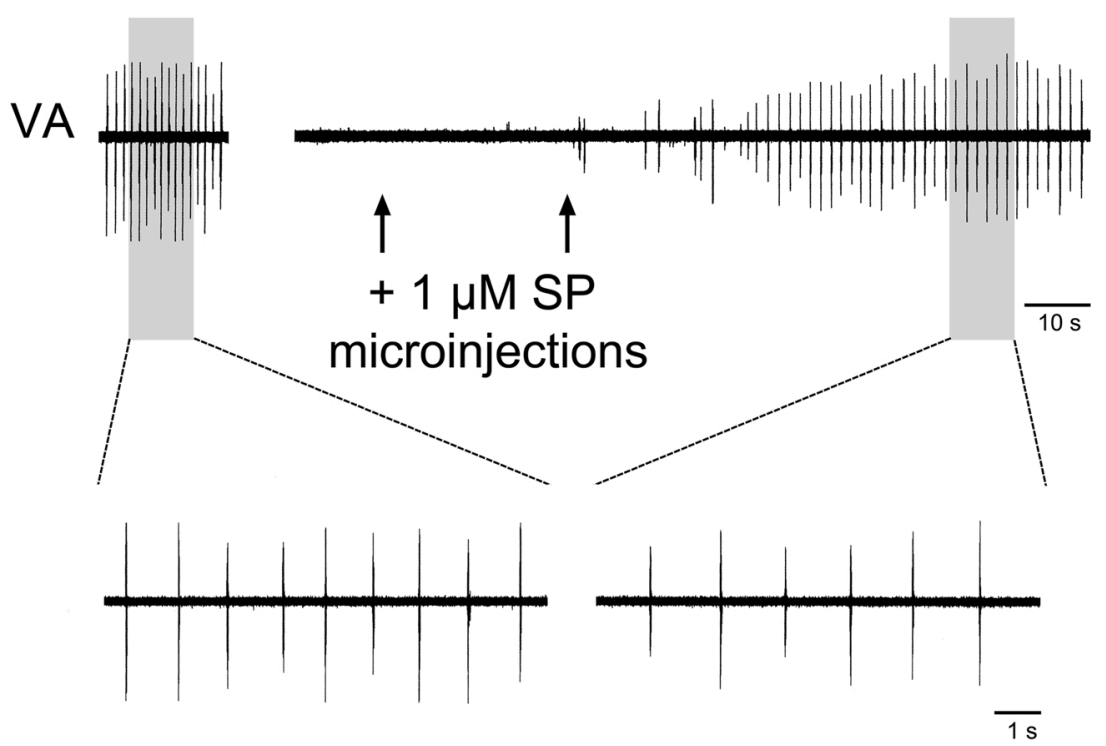

Fig. 5. Respiratory response evoked by bilateral substance $P$ (SP) microinjections into the pTRG in the presence of riluzole (RIL) and flufenamic acid (FFA) in the bath. Coapplication of RIL and FFA at $50 \mu \mathrm{M}$ (horizontal bar) abolish within $15 \mathrm{~min}$ the respiratory rhythm that is restarted by bilateral microinjections of $1 \mu \mathrm{M}$ SP (arrows) into the pTRG. The dotted lines show expanded traces during control conditions and after SP microinjections (shaded areas). VA, raw vagal nerve activity. Modified from Mutolo et al. (2010). activity by acting on $\alpha 7$ nAChRs located within the pTRG (Mutolo et al., 2011). In agreement with these findings, cholinergic neurons are found close to and intermingled with vagal projecting glutamatergic pTRG neurons possibly making synaptic contacts on their soma, thus suggesting that separate glutamatergic and cholinergic neurons exist (Cinelli et al., 2013). In addition, $\alpha$-bungarotoxin binding sites (nAChRs) are present in the PTRG area, in particular associated with the soma of neurons retrogradely labelled from the vagal area (Cinelli et al., 2013). Interestingly, during apnea caused by the blockade of ionotropic glutamate receptors the respiratory rhythm can be re-established not only by SP, as already mentioned, but also by nicotine applications to the pTRG (Cinelli et al., 2013). Taken together, these findings identify a novel cholinergic modulatory and possibly subsidiary rhythmogenic mechanism within the respiratory network of the adult lamprey. Cholinergic inputs to the PTRG may arise from several regions of the lamprey brain (Pombal et al., 2001; Le Ray et al., 2003). Among these, cholinergic cells located close to the isthmic Müller cells, i.e. near or even within the pTRG, as well as in the mesencephalic locomotor region may have a role in cholinergic modulation. The latter region is known to depolarize reticulospinal cells involved in the initiation and control of locomotion through an action on $\alpha 7$ nAChRs (Pombal et al., 2001; Le Ray et al., 2003). We can hypothesize that the mesencephalic locomotor region conveys similar cholinergic inputs to the PTRG in response to locomotion-inducing stimuli that imply a parallel activation of
A

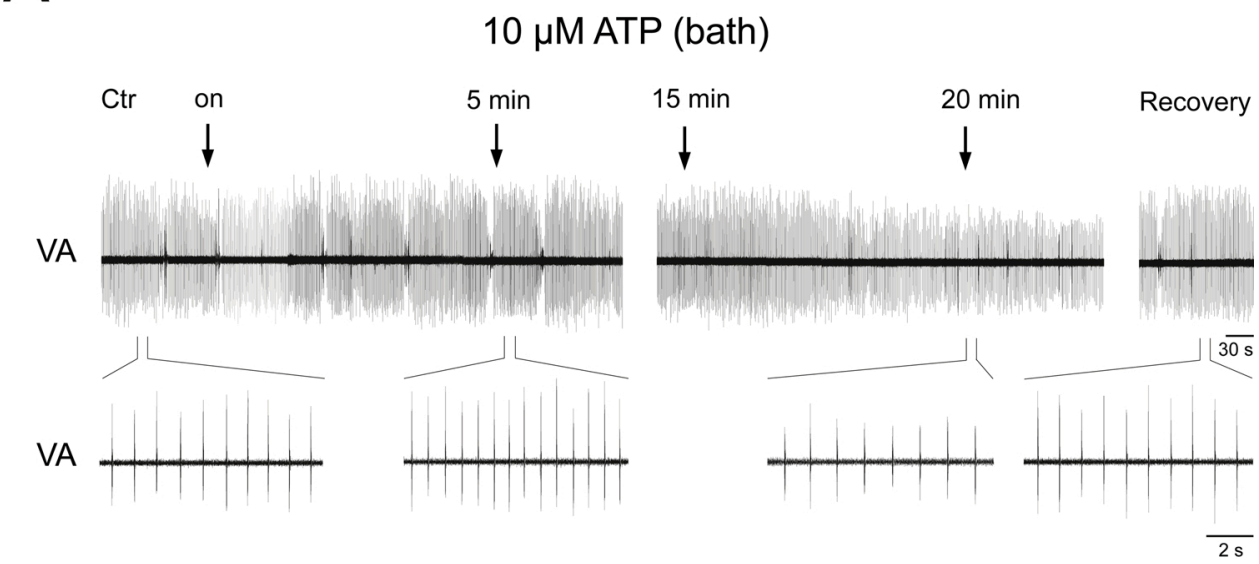

Fig. 6. Respiratory responses to ATP. A: biphasic responses induced by bath application of $10 \mu \mathrm{M}$ ATP in one preparation. Long trace recordings of raw vagal activity (VA) under control conditions (Ctr), at different times following bath application of $10 \mu \mathrm{M}$ ATP (on) and after $60 \mathrm{~min}$ washout (Recovery). Expanded traces show control baseline respiratory activity, maximum increases (5 min) and maximum decreases in respiratory activity (20 $\mathrm{min}$ ) as well as recovery. Pauses in the ongoing (fast) respiratory activity indicate the presence of 'coughs'. B: similar biphasic responses induced by bilateral microinjections of $1 \mathrm{mM}$ ATP into the pTRG in a different preparation. Modified from Cinelli et al. (2017).

B

\section{$1 \mathrm{mM}$ ATP (pTRG)}

\section{Control}

VA

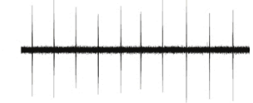

$5 \min$

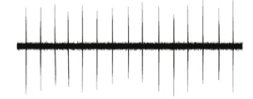

$20 \mathrm{~min}$

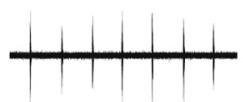

Recovery 
respiratory activity. A similar locomotor region has been described also in mammals (DiMarco et al., 1983; for a review see Grillner and El Manira, 2020).

\subsection{Purinergic signalling and astrocytes}

It is well recognised that ATP plays a role in the control of the preBötC in neonatal rodents and that astrocytes are involved in purinergic modulation (Erlichman et al., 2010; Funk et al., 2015). The function of the purinergic signalling and astrocytes within the lamprey respiratory network has been recently investigated by our group (Cinelli et al., 2017). Bath application of ATP induces a biphasic response on respiratory activity consisting of marked increases followed by decreases in respiratory frequency (Fig. 6A). These effects are exerted through an action at the level of the PTRG as shown with microinjections of ATP (Fig. 6B) and are related to ATP hydrolysis. In fact, only increases in respiratory frequency are evoked by the non-hydrolysable ATP agonist ATP- $\gamma$-S, while observed decreases in respiratory frequency are mimicked by the ATP metabolite adenosine. ATP-induced biphasic respiratory responses have been reported in previous studies on the preBötC of neonatal rats (Lorier et al., 2007; Huxtable et al., 2009; Funk, 2013). In contrast, ATP-induced increases in respiratory frequency are observed in the mouse preBötC when adenosine A1 receptors are blocked (Zwicker et al., 2011). In mice, adenosine-mediated inhibition counteracts ATP-mediated excitation due to the rapid degradation of ATP to adenosine by a specific, dominant ectonucleotidase isoform in the preBötC. Our findings indicating that adenosine causes depressant effects on respiratory activity are consistent with the results of several previous studies in different mammal species (e.g. Mironov et al., 1999; Huxtable et al., 2009; Zwicker et al., 2011; Funk, 2013). The lack of respiratory effects induced by microinjections of antagonists acting on adenosine receptors, in particular $\mathrm{A}_{1}$ receptors, and $\mathrm{P} 2$ receptors supports the view that endogenous adenosine and ATP do not exert a tonic influence on baseline respiratory activity in the lamprey. This finding does not completely rule out the existence of a tonic purinergic modulation of respiration since potential sources of ATP may be lacking in the isolated brainstem.

While the $\mathrm{P}_{2} \mathrm{Y}_{1}$ receptors are primarily involved in the ATP-evoked excitatory respiratory responses within the rodent preBötC (Lorier et al., 2007), in the lamprey the ATP-induced excitatory responses are mediated by $\mathrm{P}_{2} \mathrm{X}_{1,3}$ receptors (Cinelli et al., 2017). This difference could be possibly ascribed to the fact that the P2X receptors have been the earliest to appear during evolution and their structure and functional properties are maintained during evolution, while the metabotropic P2YRs appeared much later during evolution, more specifically in sharks and rays (Verkhratsky and Burnstock, 2014). Thus, although no information is available, to our knowledge, on the presence and cellular localization of P2 receptors in lampreys, on the basis of our microinjection studies it seems plausible that P2Y1Rs are not expressed at least within the pTRG or even in the entire lamprey brain.

To disclose the respiratory role of astrocytes, we used bath application of the gliotoxin aminoadipic acid (AAA), which dramatically depressed the respiratory motor output that, however, promptly recovered following glutamine application (Cinelli et al., 2017). Furthermore, we have shown that astrocytes are involved in the mediation of ATP-induced respiratory responses since excitatory effects are no longer evoked by ATP- $\gamma$-S microinjected into the pTRG after bath application of AAA. On the contrary, the fact that the SP microinjections into the pTRG induce excitatory effects under the same conditions strongly suggests that ATP acts mainly on astrocytes to modulate the pTRG (Cinelli et al., 2017). The possibility that astrocytes modulate and maintain the respiratory rhythm in the adult lamprey is coherent with previous findings in mammals showing that respiratory activity in medullary slices of neonatal mice and rats is markedly reduced or even blocked by using glial toxins that inhibit glial metabolism (Hülsmann et al., 2000; Huxtable et al., 2010). In addition, it has been reported that a subset of putative astrocytes from preBötC exhibited rhythmic calcium elevations preceding inspiratory neuronal activity in rhythmically active slices (Okada et al., 2012). In this connection, it could be mentioned that recently it has been shown in conscious rats that blockade of vesicular release in preBötC astrocytes reduces the breathing rate at rest and frequency of periodic sighs, decreases rhythm variability, impairs respiratory responses to hypoxia and hypercapnia, and dramatically reduces the exercise capacity, i.e. during a condition in which the increased oxygen demand must be supported by an enhanced respiratory effort (Sheikhbahaei et al., 2018). Interestingly, we also have shown that acidification-induced increases in respiratory activity were ATP-independent, but mediated by the astrocytes' glutamate-glutamine cycle (Cinelli et al., 2017).

\subsection{Serotoninergic signalling}

It is well known that in mammals 5-HT and its ionotropic and metabotropic receptors are involved in the regulation of many brain functions, including breathing (for review see Hodges and Richerson, 2008, 2010; Hilaire et al., 2010). Although different effects of 5-HT have been described on the respiratory motor output, the bulk of evidence seems to support the conclusion that 5-HT neurons play an excitatory modulation of respiratory activity (Ptak et al., 2009; Hilaire et al., 2010; Hodges and Richerson, 2010; Depuy et al., 2011; Iovino et al., 2019). This action is exerted through the combined activation of presynaptic and postsynaptic 5-HT receptors (5-HTRs) located in the respiratory neuronal structures (e.g. Hodges and Richerson, 2008, 2010; Nichols and Nichols, 2008; Dutschmann et al., 2009; Hilaire et al., 2010). In particular, it has been described at the level of the preBötC an important respiratory modulatory influence realized through $5-\mathrm{HT}_{1 \mathrm{~A}} \mathrm{R}$-mediated inhibition of glycinergic neurons in rodents and cats (Corcoran et al., 2014; Manzke et al., 2009) and of GABAergic neurons in rabbits (Iovino et al., 2019).

Given the pivotal role of $5-\mathrm{HT}_{1 \mathrm{~A}} \mathrm{Rs}$ in the modulation of locomotion (Wikstrom et al., 1995; Zhang and Grillner, 2000; Hill et al., 2003; Wang et al., 2014), a different rhythmic motor behaviour, we focused our attention on this receptor subtype (Cinelli et al., 2020b). The selective 5-HT ${ }_{1 \mathrm{~A}} \mathrm{R}$ agonists, 8-OH-DPAT and BP 554, either applied to the bath or microinjected into the PTRG do not produce any apparent respiratory effect. Thus, we examined possible tonic serotoninergic influences on respiration by bath application of the selective $5-\mathrm{HT}_{1 \mathrm{~A}} \mathrm{R}$ antagonist (S)-WAY 100135. Unexpectedly, (S)-WAY 100135 either bath applied or microinjected into the PTRG induces potent depressing respiratory effects or even apnea. These findings revealed that 5-HT exerts a 5-HT ${ }_{1 \mathrm{~A}} \mathrm{R}$-mediated potent tonic control on respiration and contributes to maintain the level of baseline respiratory activity since, when it is lacking, apnea occurs and no other mechanisms either related to 5HTRs or not, are brought into action to sustain respiration. However, the possibility that other 5HTRs could be involved in these responses should be taken into consideration. It has been shown that (S)-WAY 100135 may also act as a partial agonist of the $5-\mathrm{HT}_{1 \mathrm{D}} \mathrm{Rs}$ and, to a much lesser extent, of the 5- $\mathrm{HT}_{1 \mathrm{~B}} \mathrm{Rs}$ (Davidson et al., 1997). Interestingly, the activation of $5-\mathrm{HT}_{1 \mathrm{D}} \mathrm{Rs}$ appears to have a role in the control of the lamprey locomotor activity (Schwartz et al., 2005). Finally, an in vitro pharmacological study suggested that (S)-WAY100635 may also be a potent dopamine D4 receptor agonist (Chemel et al., 2006), but in contrast to this study, Martel et al. (2007b) reported data indicating that (S)-WAY 100635 has only modest agonist potency at D4 receptors, thus supporting the assertion that (S)-WAY 100635 is a relatively selective $5-\mathrm{HT}_{1 \mathrm{~A}} \mathrm{R}$ antagonist.

Apneic responses induced by microinjections of the $5-\mathrm{HT}_{1 \mathrm{~A}} \mathrm{R}$ antagonist into the pTRG are prevented by the blockade of $\mathrm{GABA}_{\mathrm{A}}$ or glycine receptors. The $5-\mathrm{HT}_{1 \mathrm{~A}} \mathrm{R}$-mediated inhibition is conceivably acting on glycinergic cells and GABAergic terminals, in agreement with the notion that GABAergic neurons are not present in the pTRG, but GABAimmunopositive fibres are widely distributed within this region 
(Robertson et al., 2007; Villar-Cervino et al., 2008; Cinelli et al., 2014). Immunohistochemical data are consistent with the presence of $5-\mathrm{HT}_{1 \mathrm{~A}} \mathrm{Rs}$ on glycinergic neurons at the pTRG level (Fig. 7A1-3). The circuit underlying the inhibitory mechanisms mediated by $5-\mathrm{HT}_{1 \mathrm{~A}} \mathrm{Rs}$ within the pTRG is schematically illustrated in Fig. 7B. In this model, we hypothesize that these receptors are endogenously activated and have suppressant effects on the release of inhibitory neurotransmitters, thus contributing to maintain basal respiratory activity. The blockade of $5-\mathrm{HT}_{1 \mathrm{~A}} \mathrm{Rs}$ induces apnea owing to the disinhibition of both inhibitory
GABAergic and glycinergic mechanisms acting on excitatory pTRG neurons. Apnea induced by $5-\mathrm{HT}_{1 \mathrm{~A}} \mathrm{R}$ antagonists is completely prevented by the preceding blockade of only a single inhibitory mechanism, thus suggesting synergic action of the two inhibitory mechanisms (Cinelli et al., 2020b). The lack of effects of 5- $\mathrm{HT}_{1 \mathrm{~A}} \mathrm{R}$ agonists is of difficult interpretation. The potent tonic inhibitory influence on both GABAergic and glycinergic mechanisms due to endogenously released 5-HT under basal conditions may maximally activate both pre- and postsynaptic $5-\mathrm{HT}_{1 \mathrm{~A}} \mathrm{Rs}$ and produce occlusion effects with the
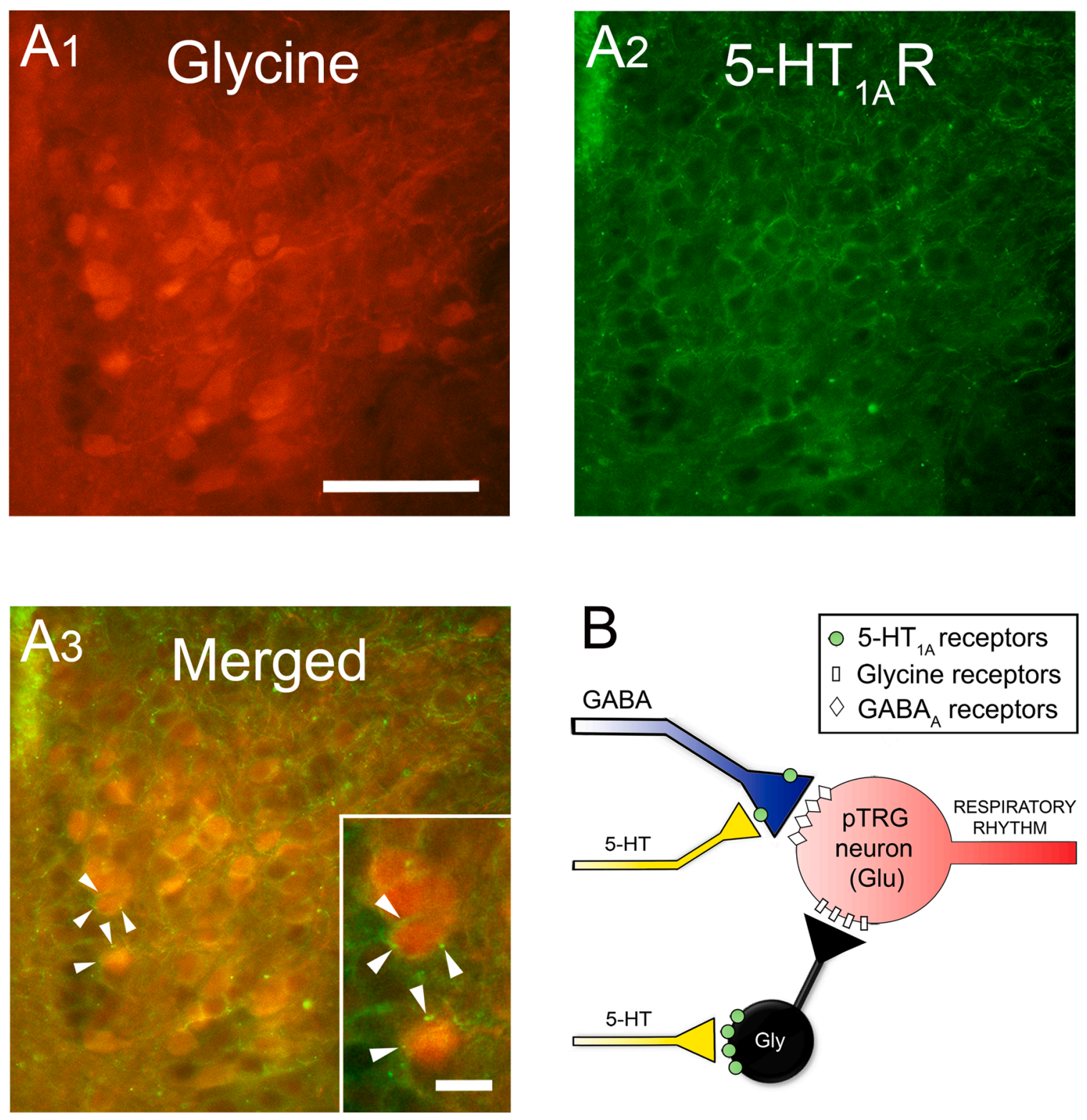

Fig. 7. Immunohistochemical labelling of glycinergic neurons and 5- $\mathrm{HT}_{1 \mathrm{~A}} \mathrm{Rs}$ in the pTRG region. A, 1-3: photomicrographs of a transverse section illustrating glycine-immunoreactive neuronal structures (panel 1, red signal), 5- $\mathrm{HT}_{1 \mathrm{~A}} \mathrm{R}$ binding sites (panel 2, green signal) and merged image (panel 3). Note the presence of 5$\mathrm{HT}_{1 \mathrm{~A}} \mathrm{R}$-like immunoreactive structures located in close apposition to glycinergic neurons. Scale bars: (panel 1-3), $50 \mu \mathrm{m}$; inset in panel 3, $10 \mu \mathrm{m}$. B: Schematic drawing representing two hypothetical inhibitory mechanisms mediated by $5-\mathrm{HT}_{1 \mathrm{~A}} \mathrm{Rs}$ within the pTRG region. Under basal conditions, both presynaptic 5 - $\mathrm{HT}_{1 \mathrm{~A}} \mathrm{Rs}$ on GABAergic terminals and postsynaptic $5-\mathrm{HT}_{1 \mathrm{~A}} \mathrm{Rs}$ on glycinergic neurons are endogenously activated and strongly reduce or completely suppress the release of the inhibitory neurotransmitters. Endogenous activation of 5- $\mathrm{HT}_{1 \mathrm{~A}} \mathrm{Rs}$ contributes to maintaining the basal rhythmic respiratory activity. The blockade of 5-HT ${ }_{1 \mathrm{~A}} \mathrm{Rs}$ by the specific antagonist (S)-WAY 100135 induces apnea owing to the disinhibition of both inhibitory GABAergic and glycinergic mechanisms acting on pTRG excitatory neurons. The blockade of both these inhibitory mechanisms completely abolishes (S)-WAY 100,135-induced apneic responses. Also the blockade of only a single inhibitory mechanism is sufficient to prevent (S)-WAY 100,135-induced apnea, thus suggesting a synergistic action of the two inhibitory neurotransmitters. Since small depressing effects on respiration occur after (S)-WAY 100,135 microinjections during glycine receptor blockade, concomitant disinhibition of the GABA release via presynaptic $5-\mathrm{HT}_{1 \mathrm{~A}} \mathrm{Rs}$ on GABAergic terminals can be suggested. On the other hand, slight depressing effects on respiration are seen after (S)-WAY 100,135 microinjections during $\mathrm{GABA}_{\mathrm{A}}$ receptor blockade, thus indicating possible associated disinhibition of pTRG glycinergic neurons operated by postsynaptic 5-HT ${ }_{1 \mathrm{~A}} \mathrm{Rs}$ located on their somata. Modified from Cinelli et al. (2020b). 
exogenously applied agonist. The results of a few trials performed in preliminary experiments in which bath application of 5-HT or citalopram, a 5-HT reuptake inhibitor, were without obvious effects on respiration are consistent with this interpretation (unpublished observations). However, the actual explanation of present results can be more complex and other 5-HTR subtypes could be involved. Also the presence of $5-\mathrm{HT}_{1 \mathrm{~A}} \mathrm{Rs}$ on the soma of 5 -HT neurons should be considered. Serotoninergic cells have been described in close vicinity to or within a region encompassing the pTRG. However, it seems plausible to suggest that projections to the PTRG may originate from the dense serotoninergic population of neurons located in the isthmic region, which corresponds to the so-called superior raphe nuclei, located in the caudal mesencephalon and rostral rhombencephalon and present in all jawed vertebrates (Abalo et al., 2007; Antri et al., 2006; Pierre et al., 1992; for further details, see also Cinelli et al., 2020b). Finally, the presence of $5-\mathrm{HT}_{1 \mathrm{~A}} \mathrm{Rs}$ on glutamatergic pTRG neurons cannot be completely excluded. However, the lack of inhibitory effects after $5-\mathrm{HT}_{1 \mathrm{~A}} \mathrm{R}$ agonist microinjections supports the notion that they are not present.

\section{Final considerations}

Attempts to draw homologies between the central respiratory rhythm generator of the lamprey and that of mammals could appear speculative since the muscles and pumps used to ventilate the respiratory system are completely different, i.e. a buccal/branchial force pump in lampreys versus an aspiration pump in mammals. However, similarly to other neurophysiological features (see e.g. Grillner and El Manira, 2020), some prominent similarities between the pTRG and the preBötC indicate that the main characteristics of the neural circuits generating respiratory rhythmic activities are highly maintained during evolution regardless of their location and their inspiratory or expiratory function. Comparative studies may provide hints for further studies on the evolutionary trends in respiratory rhythm generation and breathing control.

As the preBötC, the pTRG contains predominately glutamatergic neurons sensitive to opioids, SP and ACh. Both GABAergic and glycinergic mechanisms are involved in rhythm generation and pattern formation. Fig. 8 schematically illustrates some important connections within the lamprey respiratory network and relevant neurotransmitter influences on both the PTRG and the respiratory motoneuron region. Particularly significant, in our opinion, are the results of studies on the role of purinergic signalling and astrocytes. As we have noticed for other neural regulatory functions, these two components of brainstem networks play important modulatory roles in vertebrate respiratory

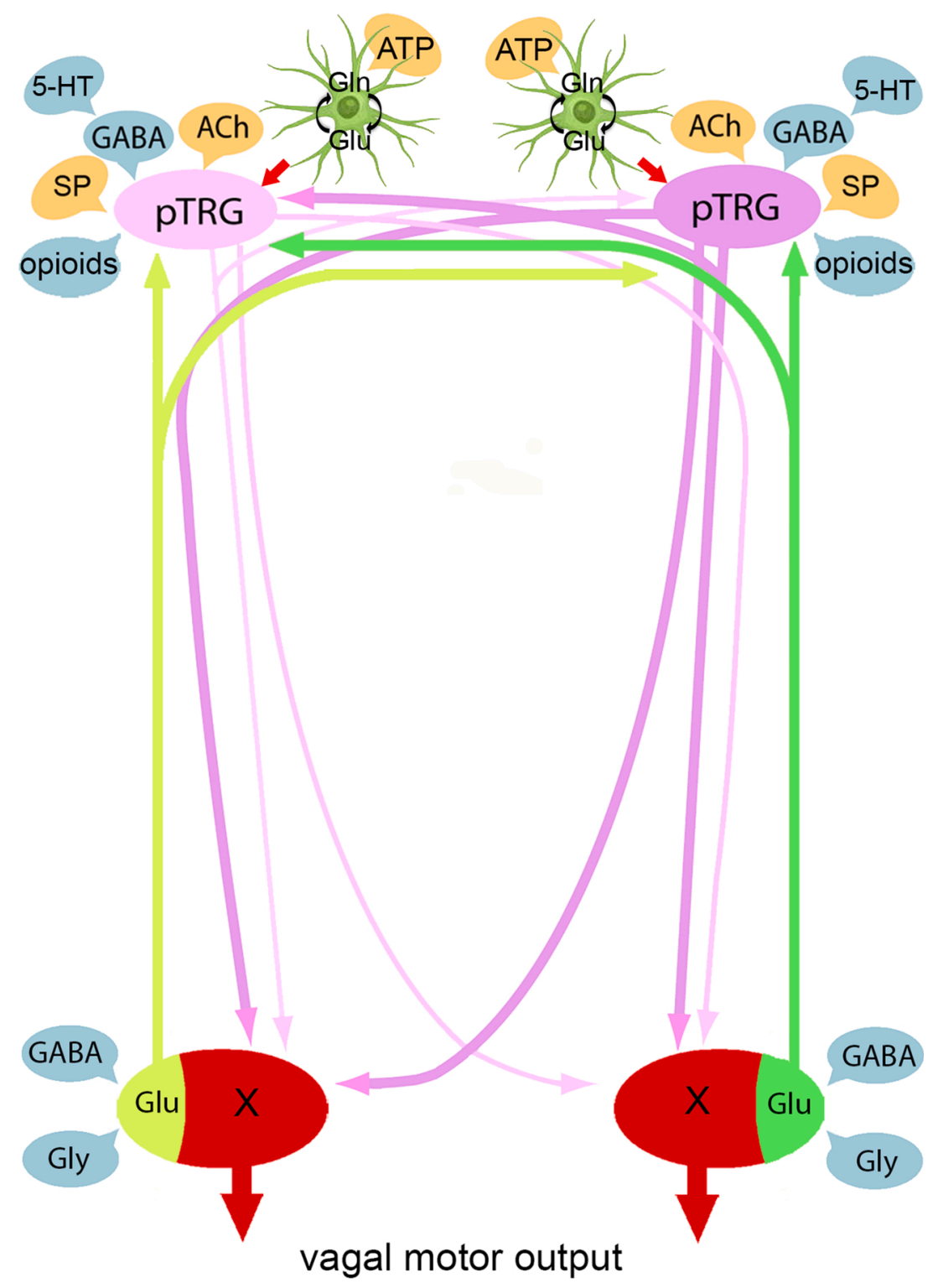

Fig. 8. Schematic drawing representing findings on the connectivity within the respiratory network and relevant neurotransmitter influences. The pTRG region is shown with its projections (pink) to ipsilateral and contralateral vagal motoneuron (red) regions and the contralateral pTRG (Gariepy et al., 2012; Cinelli et al., 2013, 2014). Excitatory (yellow) and inhibitory (blue) influences on the pTRG region (Mutolo et al., 2007, 2010, 2011; Cinelli et al., 2013, 2014, 2017; Cinelli et al., 2020b) and the vagal motoneuron region are illustrated. Glutamatergic (Glu) projections to the pTRG (green) from neurons located in the vagal area have also been reported. Astrocytes are illustrated in green. ACh, acetylcholine; GABA, $\gamma$-aminobutyric acid; Gln, glutamine; Gly, glycine; 5-HT, serotonin; pTRG, paratrigeminal respiratory group region; SP, substance P; X, vagal motoneuron region. Modified from Cinelli et al. (2014) and Bongianni et al. (2016). 
networks.

\section{Authors contributions}

All Authors prepared figures, drafted manuscript, edited and revised manuscript and approved final version of the manuscript.

\section{Acknowledgements}

This study was supported by grants from the University of Florence and from the Ente Cassa di Risparmio Firenze, Italy.

\section{References}

Abalo, X.M., Villar-Cheda, B., Melendez-Ferro, M., Perez-Costas, E., Anadon, R., Rodicio, M.C., 2007. Development of the serotonergic system in the central nervous system of the sea lamprey. J. Chem. Neuroanat. 34, 29-46.

Abbott, S.B., Stornetta, R.L., Coates, M.B., Guyenet, P.G., 2011. Phox2b-expressing neurons of the parafacial region regulate breathing rate, inspiration, and expiration in conscious rats. J. Neurosci. 31, 16410-16422.

Abdala, A.P., Rybak, I.A., Smith, J.C., Paton, J.F., 2009. Abdominal expiratory activity in the rat brainstem-spinal cord in situ: patterns, origins and implications for respiratory rhythm generation. J. Physiol. 587, 3539-3559.

Anderson, T.M., Ramirez, J.M., 2017. Respiratory rhythm generation: triple oscillator hypothesis. F1000Res. 6, 139.

Anderson, T.M., Garcia III, A.J., Baertsch, N.A., Pollak, J., Bloom, J.C., Wei, A.D., Rai, K. G., Ramirez, J.M., 2016. A novel excitatory network for the control of breathing. Nature 536, 76-80.

Antri, M., Cyr, A., Auclair, F., Dubuc, R., 2006. Ontogeny of 5-HT neurons in the brainstem of the lamprey, Petromyzon marinus. J. Comp. Neurol. 495, 788-800.

Ashhad, S., Feldman, J.L., 2020. Emergent elements of inspiratory rhythmogenesis: network synchronization and synchrony propagation. Neuron 106, 482-497 e484.

Baghdadwala, M.I., Duchcherer, M., Paramonov, J., Wilson, R.J., 2015. Three brainstem areas involved in respiratory rhythm generation in bullfrogs. J. Physiol. 593, 2941-2954.

Baghdadwala, M.I., Duchcherer, M., Trask, W.M., Gray, P.A., Wilson, R.J., 2016. Diving into the mammalian swamp of respiratory rhythm generation with the bullfrog. Respir. Physiol. Neurobiol. 224, 37-51.

Bongianni, F., Deliagina, T.G., Grillner, S., 1999. Role of glutamate receptor subtypes in the lamprey respiratory network. Brain Res. 826, 298-302.

Bongianni, F., Mutolo, D., Carfi, M., Pantaleo, T., 2002. Group I and II metabotropic glutamate receptors modulate respiratory activity in the lamprey. Eur. J. Neurosci. $16,454-460$.

Bongianni, F., Mutolo, D., Nardone, F., Pantaleo, T., 2006. GABAergic and glycinergic inhibitory mechanisms in the lamprey respiratory control. Brain Res. 1090, 134-145.

Bongianni, F., Mutolo, D., Cinelli, E., Pantaleo, T., 2008. Neurokinin receptor modulation of respiratory activity in the rabbit. Eur. J. Neurosci. 27, 3233-3243.

Bongianni, F., Mutolo, D., Cinelli, E., Pantaleo, T., 2010. Respiratory responses induced by blockades of GABA and glycine receptors within the Bötzinger complex and the pre-Bötzinger complex of the rabbit. Brain Res. 1344, 134-147.

Bongianni, F., Mutolo, D., Cinelli, E., Pantaleo, T., 2016. Neural mechanisms underlying respiratory rhythm generation in the lamprey. Respir. Physiol. Neurobiol. 224, $17-26$.

Bouverot, P., 1978. Control of breathing in birds compared with mammals. Physiol. Rev. $58,604-655$

Champagnat, J., Fortin, G., 1997. Primordial respiratory-like rhythm generation in the vertebrate embryo. Trends Neurosci. 20, 119-124.

Chemel, B.R., Roth, B.L., Armbruster, B., Watts, V.J., Nichols, D.E., 2006. WAY-100635 is a potent dopamine D4 receptor agonist. Psychopharmacology (Berl.) 188, 244-251.

Cinelli, E., Robertson, B., Mutolo, D., Grillner, S., Pantaleo, T., Bongianni, F., 2013. Neuronal mechanisms of respiratory pattern generation are evolutionary conserved. J. Neurosci. 33, 9104-9112.

Cinelli, E., Mutolo, D., Robertson, B., Grillner, S., Contini, M., Pantaleo, T., Bongianni, F., 2014. GABAergic and glycinergic inputs modulate rhythmogenic mechanisms in the lamprey respiratory network. J. Physiol. 592, 1823-1838.

Cinelli, E., Mutolo, D., Contini, M., Pantaleo, T., Bongianni, F., 2016. Inhibitory control of ascending glutamatergic projections to the lamprey respiratory rhythm generator. Neuroscience 326, 126-140.

Cinelli, E., Iovino, L., Mutolo, D., 2017. ATP and astrocytes play a prominent role in the control of the respiratory pattern generator in the lamprey. J. Physiol. 595, 7063-7079.

Cinelli, E., Bongianni, F., Pantaleo, T., Mutolo, D., 2020a. Activation of mu-opioid receptors differentially affects the preBötzinger Complex and neighbouring regions of the respiratory network in the adult rabbit. Respir. Physiol. Neurobiol. 280, 103482.

Cinelli, E., Mutolo, D., Iovino, L., Pantaleo, T., Bongianni, F., 2020b. Key role of 5-HT1A receptors in the modulation of the neuronal network underlying the respiratory rhythm generation in lampreys. Eur. J. Neurosci. 52, 3903-3917.

Connelly, C.A., Dobbins, E.G., Feldman, J.L., 1992. Pre-Bötzinger complex in cats: respiratory neuronal discharge patterns. Brain Res. 590, 337-340.
Corcoran, A.E., Commons, K.G., Wu, Y., Smith, J.C., Harris, M.B., Richerson, G.B., 2014. Dual effects of 5-HT(1a) receptor activation on breathing in neonatal mice. J. Neurosci. 34, 51-59.

Cui, Y., Kam, K., Sherman, D., Janczewski, W.A., Zheng, Y., Feldman, J.L., 2016. Defining preBötzinger complex rhythm- and pattern-generating neural microcircuits in vivo. Neuron 91, 602-614.

Davidson, C., Ho, M., Price, G.W., Jones, B.J., Stamford, J.A., 1997. (+)-WAY 100135, a partial agonist, at native and recombinant 5-HT1B/1D receptors. Br. J. Pharmacol. $121,737-742$

Del Negro, C.A., Morgado-Valle, C., Hayes, J.A., Mackay, D.D., Pace, R.W., Crowder, E. A., Feldman, J.L., 2005. Sodium and calcium current-mediated pacemaker neurons and respiratory rhythm generation. J. Neurosci. 25, 446-453.

Del Negro, C.A., Funk, G.D., Feldman, J.L., 2018. Breathing matters. Nat. Rev. Neurosci. 19, 351-367.

Depuy, S.D., Kanbar, R., Coates, M.B., Stornetta, R.L., Guyenet, P.G., 2011. Control of breathing by raphe obscurus serotonergic neurons in mice. J. Neurosci. 31, 1981-1990.

Dhingra, R.R., Furuya, W.I., Bautista, T.G., Dick, T.E., Galan, R.F., Dutschmann, M., 2019. Increasing local excitability of brainstem respiratory nuclei reveals a distributed network underlying respiratory motor pattern formation. Front. Physiol. $10,887$.

Dhingra, R.R., Dick, T.E., Furuya, W.I., Galan, R.F., Dutschmann, M., 2020. Volumetric mapping of the functional neuroanatomy of the respiratory network in the perfused brainstem preparation of rats. J. Physiol. 598, 2061-2079.

DiMarco, A.F., Romaniuk, J.R., Von Euler, C., Yamamoto, Y., 1983. Immediate changes in ventilation and respiratory pattern associated with onset and cessation of locomotion in the cat. J. Physiol. 343, 1-16.

Doi, A., Ramirez, J.M., 2008. Neuromodulation and the orchestration of the respiratory rhythm. Respir. Physiol. Neurobiol. 164, 96-104.

Douse, M.A., Mitchell, G.S., 1990. Episodic respiratory related discharge in turtle cranial motoneurons: in vivo and in vitro studies. Brain Res. 536, 297-300.

Douse, M.A., Mitchell, G.S., 1992. Episodic breathing in alligators: role of sensory feedback. Respir. Physiol. 87, 77-90.

Duchcherer, M., Kottick, A., Wilson, R.J., 2010. Evidence for a distributed respiratory rhythm generating network in the goldfish (Carsssius auratus). Adv. Exp. Med. Biol. $669,3-7$.

Dutschmann, M., Dick, T.E., 2012. Pontine mechanisms of respiratory control. Compr. Physiol. 2, 2443-2469.

Dutschmann, M., Waki, H., Manzke, T., Simms, A.E., Pickering, A.E., Richter, D.W., Paton, J.F., 2009. The potency of different serotonergic agonists in counteracting opioid evoked cardiorespiratory disturbances. Philos. Trans. R. Soc. Lond B Biol. Sci. 364, 2611-2623.

Erlichman, J.S., Leiter, J.C., Gourine, A.V., 2010. ATP, glia and central respiratory control. Respir. Physiol. Neurobiol. 173, 305-311.

Feldman, J.L., Del Negro, C.A., 2006. Looking for inspiration: new perspectives on respiratory rhythm. Nat. Rev. Neurosci. 7, 232-242.

Feldman, J.L., Smith, J.C., 1989. Cellular mechanisms underlying modulation of breathing pattern in mammals. Ann. N.Y. Acad. Sci. 563, 114-130.

Feldman, J.L., Del Negro, C.A., Gray, P.A., 2013. Understanding the rhythm of breathing: so near, yet so far. Annu. Rev. Physiol. 75, 423-452.

Fong, A.Y., Potts, J.T., 2006. Neurokinin-1 receptor activation in Bötzinger complex evokes bradypnoea. J. Physiol. 575, 869-885.

Funk, G.D., 2013. Neuromodulation: purinergic signaling in respiratory control. Compr. Physiol. 3, 331-363.

Funk, G.D., 2017. Phylogenetically persistent purinergic modulation of central pattern generators for breathing in lamprey and mammals. J. Physiol. 595, 7011-7012.

Funk, G.D., Rajani, V., Alvares, T.S., Revill, A.L., Zhang, Y., Chu, N.Y., Biancardi, V., Linhares-Taxini, C., Katzell, A., Reklow, R., 2015. Neuroglia and their roles in central respiratory control; an overview. Comp. Biochem. Physiol. A Mol. Integr. Physiol. 186, 83-95.

Gariepy, J.F., Missaghi, K., Chartre, S., Robert, M., Auclair, F., Dubuc, R., 2012. Bilateral connectivity in the brainstem respiratory networks of lampreys. J. Comp. Neurol. 520, 1442-1456.

Gray, P.A., 2013. Transcription factors define the neuroanatomical organization of the medullary reticular formation. Front. Neuroanat. 7, 7.

Gray, P.A., Rekling, J.C., Bocchiaro, C.M., Feldman, J.L., 1999. Modulation of respiratory frequency by peptidergic input to rhythmogenic neurons in the preBötzinger complex. Science 286, 1566-1568.

Gray, P.A., Janczewski, W.A., Mellen, N., McCrimmon, D.R., Feldman, J.L., 2001. Normal breathing requires preBötzinger complex neurokinin-1 receptor- expressing neurons. Nat. Neurosci. 4, 927-930.

Greer, J.J., Smith, J.C., Feldman, J.L., 1991. Role of excitatory amino acids in the generation and transmission of respiratory drive in neonatal rat. J. Physiol. 437, 727-749.

Grillner, S., 2003. The motor infrastructure: from ion channels to neuronal networks. Nat. Rev. Neurosci. 4, 573-586.

Grillner, S., 2006. Biological pattern generation: the cellular and computational logic of networks in motion. Neuron 52, 751-766.

Grillner, S., El Manira, A., 2020. Current principles of motor control, with special reference to vertebrate locomotion. Physiol. Rev. 100, 271-320.

Guimond, J.C., Auclair, F., Lund, J.P., Dubuc, R., 2003. Anatomical and physiological study of respiratory motor innervation in lampreys. Neuroscience 122, 259-266.

Hayes, J.A., Del Negro, C.A., 2007. Neurokinin receptor-expressing pre-Bötzinger complex neurons in neonatal mice studied in vitro. J. Neurophysiol. 97, 4215-4224. 
Hilaire, G., Voituron, N., Menuet, C., Ichiyama, R.M., Subramanian, H.H., Dutschmann, M., 2010. The role of serotonin in respiratory function and dysfunction. Respir. Physiol. Neurobiol. 174, 76-88.

Hill, R.H., Svensson, E., Dewael, Y., Grillner, S., 2003. 5-HT inhibits N-type but not Ltype $\mathrm{Ca}(2+)$ channels via 5-HT1A receptors in lamprey spinal neurons. Eur. J. Neurosci. 18, 2919-2924.

Hodges, M.R., Richerson, G.B., 2008. Contributions of 5-HT neurons to respiratory control: neuromodulatory and trophic effects. Respir. Physiol. Neurobiol. 164, 222-232.

Hodges, M.R., Richerson, G.B., 2010. The role of medullary serotonin (5-HT) neurons in respiratory control: contributions to eupneic ventilation, $\mathrm{CO} 2$ chemoreception, and thermoregulation. J. Appl. Physiol. 108, 1425-1432.

Hoffman, M., Taylor, B.E., Harris, M.B., 2016. Evolution of lung breathing from a lungless primitive vertebrate. Respir. Physiol. Neurobiol. 224, 11-16.

Homma, S., 1975. Velar motoneurons of lamprey larvae. J. Comp. Physiol. 104, $175-183$.

Hülsmann, S., Oku, Y., Zhang, W., Richter, D.W., 2000. Metabolic coupling between glia and neurons is necessary for maintaining respiratory activity in transverse medullary slices of neonatal mouse. Eur. J. Neurosci. 12, 856-862.

Huxtable, A.G., Zwicker, J.D., Poon, B.Y., Pagliardini, S., Vrouwe, S.Q., Greer, J.J., Funk, G.D., 2009. Tripartite purinergic modulation of central respiratory networks during perinatal development: the influence of ATP, ectonucleotidases, and ATP metabolites. J. Neurosci. 29, 14713-14725.

Huxtable, A.G., Zwicker, J.D., Alvares, T.S., Ruangkittisakul, A., Fang, X., Hahn, L.B., Posse, d.C., Baker, G.B., Ballanyi, K., Funk, G.D., 2010. Glia contribute to the purinergic modulation of inspiratory rhythm-generating networks. J. Neurosci. 30, 3947-3958.

Iovino, L., Mutolo, D., Cinelli, E., Contini, M., Pantaleo, T., Bongianni, F., 2019. Breathing stimulation mediated by 5-HT1A and 5-HT3 receptors within the preBötzinger complex of the adult rabbit. Brain Res. 1704, 26-39.

Janczewski, W.A., Feldman, J.L., 2006. Distinct rhythm generators for inspiration and expiration in the juvenile rat. J. Physiol. 570, 407-420.

Janczewski, W.A., Tashima, A., Hsu, P., Cui, Y., Feldman, J.L., 2013. Role of inhibition in respiratory pattern generation. J. Neurosci. 33, 5454-5465.

Janes, T.A., Rousseau, J.P., Fournier, S., Kiernan, E.A., Harris, M.B., Taylor, B.E., Kinkead, R., 2019. Development of central respiratory control in anurans: the role of neurochemicals in the emergence of air-breathing and the hypoxic response. Respir. Physiol. Neurobiol. 270, 103266.

Johnson, S.M., Mitchell, G.S., 1998. N-methyl-D-aspartate-mediated bulbospinal respiratory drive is $\mathrm{pH} / \mathrm{P}(\mathrm{CO} 2)$-insensitive in turtle brainstem-spinal cord. Respir. Physiol. 113, 201-212.

Johnson, S.M., Johnson, R.A., Mitchell, G.S., 1998. Hypoxia, temperature, and pH/CO effects on respiratory discharge from a turtle brain stem preparation. J. Appl. Physiol. 84, 649-660.

Johnson, S.M., Wilkerson, J.E., Wenninger, M.R., Henderson, D.R., Mitchell, G.S., 2002. Role of synaptic inhibition in turtle respiratory rhythm generation. J. Physiol. 544 253-265.

Johnson, S.M., Wiegel, L.M., Majewski, D.J., 2007. Are pacemaker properties required for respiratory rhythm generation in adult turtle brain stems in vitro? Am. J. Physiol. Regul. Integr. Comp. Physiol. 293, R901-910.

Johnson, S.M., Hedrick, M.S., Krause, B.M., Nilles, J.P., Chapman, M.A., 2016. Respiratory neuron characterization reveals intrinsic bursting properties in isolated adult turtle brainstems (Trachemys scripta). Respir. Physiol. Neurobiol. 224, 52-61.

Jones, S.E., Dutschmann, M., 2016. Testing the hypothesis of neurodegeneracy in respiratory network function with a priori transected arterially perfused brain stem preparation of rat. J. Neurophysiol. 115, 2593-2607.

Kam, K., Worrell, J.W., Janczewski, W.A., Cui, Y., Feldman, J.L., 2013. Distinct inspiratory rhythm and pattern generating mechanisms in the preBötzinger complex. J. Neurosci. 33, 9235-9245.

Kinkead, R., 2009. Phylogenetic trends in respiratory rhythmogenesis: insights from ectothermic vertebrates. Respir. Physiol. Neurobiol. 168, 39-48.

Kinkead, R., Milsom, W.K., 1997. Role of pulmonary stretch receptor feedback in control of episodic breathing in the bullfrog. Am. J. Physiol. Regul. Integr. Comp. Physiol. 272, R497-R508.

Kumar, S., Hedges, S.B., 1998. A molecular timescale for vertebrate evolution. Nature 392, 917-920.

Le Ray, D., Brocard, F., Bourcier-Lucas, C., Auclair, F., Lafaille, P., Dubuc, R., 2003. Nicotinic activation of reticulospinal cells involved in the control of swimming in lampreys. Eur. J. Neurosci. 17, 137-148.

Lorier, A.R., Huxtable, A.G., Robinson, D.M., Lipski, J., Housley, G.D., Funk, G.D., 2007. $\mathrm{P} 2 \mathrm{Y} 1$ receptor modulation of the preBötzinger complex inspiratory rhythm generating network in vitro. J. Neurosci. 27, 993-1005.

Manzke, T., Dutschmann, M., Schlaf, G., Morschel, M., Koch, U.R., Ponimaskin, E., Bidon, O., Lalley, P.M., Richter, D.W., 2009. Serotonin targets inhibitory synapses to induce modulation of network functions. Philos. Trans. R. Soc. Lond B Biol. Sci 364, 2589-2602.

Martel, B., Guimond, J.C., Gariepy, J.F., Gravel, J., Auclair, F., Kolta, A., Lund, J.P., Dubuc, R., 2007a. Respiratory rhythms generated in the lamprey rhombencephalon. Neuroscience 148, 279-293.

Martel, J.-C., Leduc, N., Ormière, A.-M., Faucillon, V., Danty, N., Culie, C., Cussac, D., Newman-Tancredi, A., 2007b. WAY-100635 has high selectivity for serotonin 5HT1A versus dopamine D4 receptors. Eur. J. Pharmacol. 574, 15-19.

McKay, L.C., Janczewski, W.A., Feldman, J.L., 2005. Sleep-disordered breathing after targeted ablation of preBötzinger complex neurons. Nat. Neurosci. 8, 1142-1144.

Milsom, W.K., 1991. Intermittent breathing in vertebrates. Annu. Rev. Physiol. 53, 87-105.
Milsom, W.K., 2010. Adaptive trends in respiratory control: a comparative perspective. Am. J. Physiol. Regul. Integr. Comp. Physiol. 299, R1-10.

Milsom, W.K., 2018. Central control of air breathing in fishes. Acta Histochem. 120, 691-700.

Milsom, W.K., Jackson, D.C., 2011. Hibernation and gas exchange. Compr. Physiol. 1, 397-420.

Mironov, S.L., Langohr, K., Richter, D.W., 1999. A1 adenosine receptors modulate respiratory activity of the neonatal mouse via the cAMP-mediated signaling pathway. J. Neurophysiol. 81, 247-255.

Missaghi, K., Le Gal, J.P., Gray, P.A., Dubuc, R., 2016. The neural control of respiration in lampreys. Respir. Physiol. Neurobiol. 234, 14-25.

Montandon, G., Qin, W., Liu, H., Ren, J., Greer, J.J., Horner, R.L., 2011. PreBötzinger complex neurokinin-1 receptor-expressing neurons mediate opioid-induced respiratory depression. J. Neurosci. 31, 1292-1301.

Montandon, G., Liu, H., Horner, R.L., 2016. Contribution of the respiratory network to rhythm and motor output revealed by modulation of GIRK channels, somatostatin and neurokinin-1 receptors. Sci. Rep. 6, 32707.

Murakami, Y., Pasqualetti, M., Takio, Y., Hirano, S., Rijli, F.M., Kuratani, S., 2004. Segmental development of reticulospinal and branchiomotor neurons in lamprey: insights into the evolution of the vertebrate hindbrain. Development 131, 983-995.

Mutolo, D., 2017. Brainstem mechanisms underlying the cough reflex and its regulation. Respir. Physiol. Neurobiol. 243, 60-76.

Mutolo, D., Bongianni, F., Carfi, M., Pantaleo, T., 2002. Respiratory changes induced by kainic acid lesions in rostral ventral respiratory group of rabbits. Am. J. Physiol. Regul. Integr. Comp. Physiol. 283, R227-R242.

Mutolo, D., Bongianni, F., Nardone, F., Pantaleo, T., 2005. Respiratory responses evoked by blockades of ionotropic glutamate receptors within the Bötzinger complex and the pre-Bötzinger complex of the rabbit. Eur. J. Neurosci. 21, 122-134.

Mutolo, D., Bongianni, F., Einum, J., Dubuc, R., Pantaleo, T., 2007. Opioid-induced depression in the lamprey respiratory network. Neuroscience 150, 720-729.

Mutolo, D., Bongianni, F., Cinelli, E., Pantaleo, T., 2010. Role of neurokinin receptors and ionic mechanisms within the respiratory network of the lamprey. Neuroscience 169, 1136-1149.

Mutolo, D., Cinelli, E., Bongianni, F., Pantaleo, T., 2011. Identification of a cholinergic modulatory and rhythmogenic mechanism within the lamprey respiratory network. J. Neurosci. 31, 13323-13332.

Nichols, D.E., Nichols, C.D., 2008. Serotonin receptors. Chem. Rev. 108, 1614-1641.

Okada, Y., Sasaki, T., Oku, Y., Takahashi, N., Seki, M., Ujita, S., Tanaka, K.F., Matsuki, N., Ikegaya, Y., 2012. Preinspiratory calcium rise in putative preBötzinger complex astrocytes. J. Physiol. 590, 4933-4944.

Pantaleo, T., Mutolo, D., Cinelli, E., Bongianni, F., 2011. Respiratory responses to somatostatin microinjections into the Bötzinger complex and the pre-Bötzinger complex of the rabbit. Neurosci. Lett. 498, 26-30.

Peña, F., Ramirez, J.M., 2004. Substance P-mediated modulation of pacemaker properties in the mammalian respiratory network. J. Neurosci. 24, 7549-7556.

Pierre, J., Reperant, J., Ward, R., Vesselkin, N.P., Rio, J.P., Miceli, D., Kratskin, I., 1992. The serotoninergic system of the brain of the lamprey, Lampetra fluviatilis: an evolutionary perspective. J. Chem. Neuroanat. 5, 195-219.

Pombal, M.A., Marin, O., Gonzalez, A., 2001. Distribution of choline acetyltransferaseimmunoreactive structures in the lamprey brain. J. Comp. Neurol. 431, 105-126.

Ptak, K., Yamanishi, T., Aungst, J., Milescu, L.S., Zhang, R., Richerson, G.B., Smith, J.C., 2009. Raphe neurons stimulate respiratory circuit activity by multiple mechanisms via endogenously released serotonin and substance P. J. Neurosci. 29, 3720-3737.

Qi, J., Li, H., Zhao, T.B., Lu, Y.C., Zhang, T., Li, J.L., Dong, Y.L., Li, Y.Q., 2017. Inhibitory effect of Endomorphin-2 binding to the mu-opioid receptor in the rat pre-bötzinger complex on the breathing activity. Mol. Neurobiol. 54, 461-469.

Ramirez, J.M., Baertsch, N.A., 2018. The dynamic basis of respiratory rhythm generation: one breath at a time. Annu. Rev. Neurosci. 41, 475-499.

Ramirez, J.M., Quellmalz, U.J., Richter, D.W., 1996. Postnatal changes in the mammalian respiratory network as revealed by the transverse brainstem slice of mice. J. Physiol. 491, 799-812.

Ramirez, J.M., Schwarzacher, S.W., Pierrefiche, O., Olivera, B.M., Richter, D.W., 1998. Selective lesioning of the cat pre-Bötzinger complex in vivo eliminates breathing but not gasping. J. Physiol. 507, 895-907.

Ramirez, J.M., Dashevskiy, T., Marlin, I.A., Baertsch, N., 2016. Microcircuits in respiratory rhythm generation: commonalities with other rhythm generating networks and evolutionary perspectives. Curr. Opin. Neurobiol. 41, 53-61.

Rekling, J.C., Feldman, J.L., 1998. PreBötzinger complex and pacemaker neurons: hypothesized site and kernel for respiratory rhythm generation. Annu. Rev. Physiol. 60, 385-405.

Richter, D.W., 1982. Generation and maintenance of the respiratory rhythm. J. Exp. Biol. 100, 93-107.

Robertson, B., Auclair, F., Menard, A., Grillner, S., Dubuc, R., 2007. GABA distribution in lamprey is phylogenetically conserved. J. Comp. Neurol. 503, 47-63.

Rovainen, C.M., 1974. Respiratory motoneurons in lampreys. J.Comp.Physiol. 94, 57-68.

Rovainen, C.M., 1977. Neural control of ventilation in the lamprey. Fed. Proc. 36, 2386-2389.

Rovainen, C.M., 1979. Neurobiology of lampreys. Physiol. Rev. 59, 1007-1077.

Rovainen, C.M., 1983. Generation of respiratory activity by the lamprey brain exposed to picrotoxin and strychnine, and weak synaptic inhibition in motoneurons. Neuroscience 10, 875-882.

Rovainen, C.M., 1985. Respiratory bursts at the midline of the rostral medulla of the lamprey. J. Comp. Physiol. [A] 157, 303-309.

Rovainen, C.M., 1996. Feeding and breathing in lampreys. Brain Behav. Evol. 48, 297-305. 
Russell, D.F., 1986. Respiratory pattern generation in adult lampreys (Lampetra fluviatilis): interneurons and burst resetting. J. Comp. Physiol. [A] 158, 91-102.

Schwartz, E.J., Gerachshenko, T., Alford, S., 2005. 5-HT prolongs ventral root bursting via presynaptic inhibition of synaptic activity during fictive locomotion in lamprey. J. Neurophysiol. 93, 980-988.

Schwarzacher, S.W., Smith, J.C., Richter, D.W., 1995. Pre-Bötzinger complex in the cat. J. Neurophysiol. 73, 1452-1461.

Schwarzacher, S.W., Rub, U., Deller, T., 2011. Neuroanatomical characteristics of the human pre-Bötzinger complex and its involvement in neurodegenerative brainstem diseases. Brain 134, 24-35.

Shao, X.M., Feldman, J.L., 2000. Acetylcholine modulates respiratory pattern: effects mediated by M3-like receptors in preBötzinger complex inspiratory neurons. J. Neurophysiol. 83, 1243-1252.

Shao, X.M., Feldman, J.L., 2001. Mechanisms underlying regulation of respiratory pattern by nicotine in preBötzinger complex. J. Neurophysiol. 85, 2461-2467.

Shao, X.M., Feldman, J.L., 2009. Central cholinergic regulation of respiration: nicotinic receptors. Acta Pharmacol. Sin. 30, 761-770.

Sheikhbahaei, S., Turovsky, E.A., Hosford, P.S., Hadjihambi, A., Theparambil, S.M., Liu, B., Marina, N., Teschemacher, A.G., Kasparov, S., Smith, J.C., Gourine, A.V., 2018. Astrocytes modulate brainstem respiratory rhythm-generating circuits and determine exercise capacity. Nat. Commun. 9, 370.

Sherman, D., Worrell, J.W., Cui, Y., Feldman, J.L., 2015. Optogenetic perturbation of preBötzinger complex inhibitory neurons modulates respiratory pattern. Nat. Neurosci. 18, 408-414.

Smith, J.C., Ellenberger, H.H., Ballanyi, K., Richter, D.W., Feldman, J.L., 1991. PreBötzinger complex: a brainstem region that may generate respiratory rhythm in mammals. Science 254, 726-729.

Smith, J.C., Butera, R.J., Koshiya, N., Del Negro, C., Wilson, C.G., Johnson, S.M., 2000. Respiratory rhythm generation in neonatal and adult mammals: the hybrid pacemaker-network model. Respir. Physiol. 122, 131-147.

Smith, J.C., Abdala, A.P., Koizumi, H., Rybak, I.A., Paton, J.F., 2007. Spatial and functional architecture of the mammalian brain stem respiratory network: a hierarchy of three oscillatory mechanisms. J. Neurophysiol. 98, 3370-3387.

St Jacques, R., St John, W.M., 1999. Transient, reversible apnoea following ablation of the pre-Bötzinger complex in rats. J. Physiol. 520, 303-314.

Straus, C., Wilson, R.J.A., Tezenas du Montcel, S., Remmers, J.E., 2000. Baclofen eliminates cluster lung breathing of the tadpole brainstem, in vitro. Neurosci. Lett. 292, 13-16.

Sun, Q.J., Goodchild, A.K., Chalmers, J.P., Pilowsky, P.M., 1998. The pre-Bötzinger complex and phase-spanning neurons in the adult rat. Brain Res. 809, 204-213.

Sun, X., Thorn Perez, C., Halemani, D.N., Shao, X.M., Greenwood, M., Heath, S., Feldman, J.L., Kam, K., 2019. Opioids modulate an emergent rhythmogenic process to depress breathing. Elife 8 .

Takeda, R., Remmers, J.E., Baker, J.P., Madden, K.P., Farber, J.P., 1986. Postsynaptic potentials of bulbar respiratory neurons of the turtle. Respir. Physiol. 64, 149-160.

Taylor, E.W., 1992. Nervous control of the heart and cardiorespiratory interactions. In: Hoar, W.S., R.D.J (Eds.), Fish Physiology. Academic press, New York, pp. 343-387.

Taylor, E.W., Jordan, D., Coote, J.H., 1999. Central control of the cardiovascular and respiratory systems and their interactions in vertebrates. Physiol. Rev. 79, 855-916.

Taylor, E.W., Leite, C.A., Florindo, L.H., Belao, T., Rantin, F.T., 2009. The basis of vagal efferent control of heart rate in a neotropical fish, the pacu, Piaractus mesopotamicus. J. Exp. Biol. 212, 906-913.
Taylor, E.W., Leite, C.A., McKenzie, D.J., Wang, T., 2010. Control of respiration in fish, amphibians and reptiles. Braz. J. Med. Biol. Res. 43, 409-424.

Thompson, K.J., 1985. Organization of inputs to motoneurons during fictive respiration in the isolated lamprey brain. J. Comp. Physiol. [A] 157, 291-302.

Toor, R., Sun, Q.J., Kumar, N.N., Le, S., Hildreth, C.M., Phillips, J.K., McMullan, S., 2019. Neurons in the intermediate reticular nucleus coordinate postinspiratory activity, swallowing, and respiratory-sympathetic coupling in the rat. J. Neurosci. 39, 9757-9766.

Tupal, S., Rieger, M.A., Ling, G.Y., Park, T.J., Dougherty, J.D., Goodchild, A.K., Gray, P. A., 2014. Testing the role of preBötzinger Complex somatostatin neurons in respiratory and vocal behaviors. Eur. J. Neurosci. 40, 3067-3077.

Verkhratsky, A., Burnstock, G., 2014. Biology of purinergic signalling: its ancient evolutionary roots, its omnipresence and its multiple functional significance. Bioessays 36, 697-705.

Villar-Cervino, V., Barreiro-Iglesias, A., Anadon, R., Rodicio, M.C., 2008. Distribution of glycine immunoreactivity in the brain of adult sea lamprey (Petromyzon marinus). Comparison with gamma-aminobutyric acid. J. Comp. Neurol. 507, 1441-1463.

Vincen-Brown, M.A., Whitesitt, K.C., Quick, F.G., Pilarski, J.Q., 2016. Studying respiratory rhythm generation in a developing bird: hatching a new experimental model using the classic in vitro brainstem-spinal cord preparation. Respir. Physiol. Neurobiol. 224, 62-70.

Von Euler, C., 1997. Neural organization and rhythm generation. In: Crystal, R.G., West, J.B., Barnes, P.J., Weibel, E.R. (Eds.), The Lung: Scientific Foundations, second edition ed. Lippincott-Raven, Philadelphia, pp. 1711-1724.

Wallen-Mackenzie, A., Gezelius, H., Thoby-Brisson, M., Nygard, A., Enjin, A., Fujiyama, F., Fortin, G., Kullander, K., 2006. Vesicular glutamate transporter 2 is required for central respiratory rhythm generation but not for locomotor central pattern generation. J. Neurosci. 26, 12294-12307.

Wang, H., Germanson, T.P., Guyenet, P.G., 2002. Depressor and tachypneic responses to chemical stimulation of the ventral respiratory group are reduced by ablation of neurokinin-1 receptor-expressing neurons. J. Neurosci. 22, 3755-3764.

Wang, D., Grillner, S., Wallen, P., 2014. Endogenous release of 5-HT modulates the plateau phase of NMDA-induced membrane potential oscillations in lamprey spinal neurons. J. Neurophysiol. 112, 30-38.

Wenninger, J.M., Pan, L.G., Klum, L., Leekley, T., Bastastic, J., Hodges, M.R., Feroah, T. R., Davis, S., Forster, H.V., 2004. Large lesions in the pre-Bötzinger complex area eliminate eupneic respiratory rhythm in awake goats. J. Appl. Physiol. 97, 1629-1636.

Whitaker-Fornek, J.R., Nelson, J.K., Lybbert, C.W., Pilarski, J.Q., 2019. Development and regulation of breathing rhythms in embryonic and hatchling birds. Respir. Physiol. Neurobiol. 269, 103246.

Wikstrom, M., Hill, R., Hellgren, J., Grillner, S., 1995. The action of 5-HT on calciumdependent potassium channels and on the spinal locomotor network in lamprey is mediated by 5-HT1A-like receptors. Brain Res. 678, 191-199.

Wilson, R.J., Vasilakos, K., Harris, M.B., Straus, C., Remmers, J.E., 2002. Evidence that ventilatory rhythmogenesis in the frog involves two distinct neuronal oscillators. J. Physiol. 540, 557-570.

Zhang, W., Grillner, S., 2000. The spinal 5-HT system contributes to the generation of fictive locomotion in lamprey. Brain Res. 879, 188-192.

Zwicker, J.D., Rajani, V., Hahn, L.B., Funk, G.D., 2011. Purinergic modulation of preBötzinger complex inspiratory rhythm in rodents: the interaction between ATP and adenosine. J. Physiol. 589, 4583-4600. 